\title{
The Long-Term Impact of the Market Stability Reserve on the EU Emission Trading System
}

\author{
Kenneth Bruninx ${ }^{\mathrm{a}, \mathrm{b}, \mathrm{c}, *}$, Marten Ovaere ${ }^{\mathrm{d}, \mathrm{e}}$, Erik Delarue $^{\mathrm{a}, \mathrm{c}}$ \\ ${ }^{a}$ Division of Applied Mechanics 8 Energy Conversion, Mechanical Engineering, KU Leuven \\ ${ }^{b}$ VITO, The Flemish Institute for Technological Research \\ ${ }^{c}$ Energy Ville, a joint venture of KU Leuven, VITO \& IMEC \\ ${ }^{d}$ School of Forestry $\&$ Environmental Studies, Yale University \\ ${ }^{e}$ Department of Economics, KU Leuven
}

\begin{abstract}
To provide a strong price signal for greenhouse gas emissions abatement, Europe decided to strengthen the European Union Emissions Trading System (EU ETS) by implementing a market stability reserve (MSR) that includes a cancellation policy and to increase the linear reduction factor from $1.74 \%$ to $2.2 \%$ after 2020 . Results of a detailed long-term investment model, formulated as a large-scale mixed complementary problem, show that this strengthened EU ETS may quadruple EUA prices and may decrease cumulative $\mathrm{CO}_{2}$ emissions with $21.3 \mathrm{GtCO}_{2}$ compared to the cumulative cap before the strengthening $\left(52.2 \mathrm{GtCO}_{2}\right)$. Around $40 \%$ of this decrease $\left(8.3 \mathrm{GtCO}_{2}\right)$ is due to the increased linear reduction factor and $60 \%$ due to the cancellation policy $\left(13 \mathrm{GtCO}_{2}\right)$. Without the increased linear reduction factor, the MSR's cancellation policy would decrease emissions by only $4.1 \mathrm{GtCO}_{2}$, indicating their complementarity. A sensitivity analysis on key model assumptions and parameters reveals that the impact of the MSR is, however, strongly dependent on other policies (e.g., renewable energy targets, nuclear, lignite and coal phase-outs) and cost evolutions of abatement options (e.g., investment cost reductions for wind and solar power). This renders the effective $\mathrm{CO}_{2}$ emissions cap highly uncertain. In our simulation results, cancellation volumes range between 5.6 and $17.8 \mathrm{GtCO}_{2}$, which is to be compared with our central estimate of $13 \mathrm{GtCO}_{2}$. We calculate the required linear reduction factors to achieve these $\mathrm{CO}_{2}$ emission reductions without an MSR, which would remove all uncertainty on the cumulative $\mathrm{CO}_{2}$ emissions and interference with other complementary climate or energy policies.
\end{abstract}

Keywords: European Emission Trading System, Market Stability Reserve, Carbon Price, Electricity Generation, Mixed Complementarity Problem, Alternating Direction Method of Multipliers

\footnotetext{
* Corresponding author

Email address: kenneth.bruninx@kuleuven.be (Kenneth Bruninx)
} 


\section{Nomenclature}

\section{Sets}

$\mathcal{D}$

$\mathcal{H}$

$\mathcal{M}$

$\mathcal{P}$

$\mathcal{R}$

$\mathcal{Y}$

\section{Variables}

$b_{y, p}^{\mathrm{C}}, b_{y}^{\mathrm{I}}$

$c_{y, m}^{\mathrm{MSR}}$

$c p_{y, p}^{\mathrm{C}}, c p_{y, r}^{\mathrm{R}}$

$e_{y}^{\mathrm{I}}$

$g_{y, d, h, p}^{\mathrm{C}}, g_{y, d, h, r}^{\mathrm{R}}$

$g_{y, r}^{\mathrm{R}, \mathrm{NB}}$

$\lambda_{y}^{\mathrm{ETS}}$

$\lambda_{y, d, h}^{\mathrm{EOM}}$

$\lambda_{y}^{\mathrm{REC}}$

$m s r_{y, m}$
Set of representative days, indexed by $d$.

Set of hourly time steps, indexed by $h$.

Set of months, indexed by $m$.

Set of conventional power plant technologies, indexed by $p$, with cardinality $N^{\mathrm{P}}$.

Set of renewable electricity generation technologies, indexed by $r$, with cardinality $N^{\mathrm{R}}$.

Set of years, indexed by $y$, with cardinality $N^{\mathrm{Y}}$.

EUAs procured in year $y$ for $\mathrm{CO}_{2}$ emissions caused by conventional electricity generation technology $p(\mathrm{C})$ or industry (I), $\mathrm{tCO}_{2}$.

Cancellation of EUAs in month $m$ of year $y, \mathrm{tCO}_{2}$.

Capacity investment in power plant technology $p$ or RES-based generation $r$ in year $y$, MW.

$\mathrm{CO}_{2}$ emissions of the energy-intensive industry in year $y, \mathrm{tCO}_{2}$.

Output associated with power plant technology $p$ or RES $r$ in hour $h$ of day $d$ of year $y$, MWh.

Annual output associated with newly constructed RES-based technology $r$ in year $y$, MWh.

Emission allowance price in year $y, € / \mathrm{tCO}_{2}$.

Energy price in hour $h$ of representative day $d$ of year $y$, $€ /$ MWh.

Renewable energy certificate (REC) price in year $y, € / M W h$.

Content of the MSR in month $m$ of year $y, \mathrm{tCO}_{2}$. 


\begin{tabular}{|c|c|}
\hline$R^{\mathrm{EOM}, \mathrm{i}}, R^{\mathrm{REC}, \mathrm{i}}, R^{\mathrm{ETS}, \mathrm{i}}$ & $\begin{array}{l}\text { Primal residuals on the energy only market, renewable certifi- } \\
\text { cates auctions and ETS auctions in iteration } i, \mathrm{MWh} \text { or } \mathrm{tCO}_{2} \text {. }\end{array}$ \\
\hline$R_{p}^{\mathrm{C}, \mathrm{i}}, R_{r}^{\mathrm{R}, \mathrm{i}}, R^{\mathrm{IND}, \mathrm{i}}$ & $\begin{array}{l}\text { Dual residuals on the strategies of conventional generator } p \text {, re- } \\
\text { newable generator } r \text { or the energy-intensive industry in iteration } \\
i, € \text {. }\end{array}$ \\
\hline$S_{y}$ & $\begin{array}{l}\text { Supply of EU emission allowances after correction for transfers } \\
\text { to and from the market stability reserve in each year } y, \mathrm{tCO}_{2} \text {. }\end{array}$ \\
\hline $\operatorname{tnac}_{y}$ & $\begin{array}{l}\text { Total number of allowances in circulation at the end of each year } \\
y, \mathrm{tCO}_{2} \text {. }\end{array}$ \\
\hline$x_{y, m}^{\mathrm{MSR}}$ & Inflow or outflow of the MSR in month $m$ of year $y, \mathrm{tCO}_{2}$. \\
\hline \multicolumn{2}{|l|}{ Parameters } \\
\hline$\delta$ & Tolerance of the ADMM algorithm. \\
\hline$\delta_{y}$ & $\begin{array}{l}\text { Inflow of back-loaded or unallocated allowances to the MSR in } \\
\text { year } y, \mathrm{tCO}_{2} \text {. }\end{array}$ \\
\hline$\rho$ & $\begin{array}{l}\text { Parameter controlling the price update step size in the ADMM } \\
\text { algorithm. }\end{array}$ \\
\hline$A_{y}, A_{y}^{\mathrm{SP}}$ & Discount factor, calculated as $\frac{1}{(1+r)^{y}}$ with $r$ the discount rate. \\
\hline$A V_{h, r}$ & Availability of renewable energy source $r$ in hour $h$. \\
\hline$C I_{p}$ & $\begin{array}{l}\text { Carbon intensity of conventional power plant technology } p \text {, } \\
\mathrm{tCO}_{2} / \mathrm{MWh} \text {. }\end{array}$ \\
\hline$\overline{C P_{y, p}}, \overline{C P_{y, r}}$ & $\begin{array}{l}\text { Available legacy capacity of power plant technology } p \text { or } r \text { in } \\
\text { year } y, \text { MW. }\end{array}$ \\
\hline$D_{y, d, h}$ & $\begin{array}{l}\text { Hourly demand for electricity in hour } h \text { in representative day } d \\
\text { of year } y, \text { MWh. }\end{array}$ \\
\hline $\mathcal{F}_{y}\left(\lambda_{y}^{\mathrm{ETS}}\right)$ & $\begin{array}{l}\text { Relation between } \mathrm{CO}_{2} \text { emissions from the energy-intensive in- } \\
\text { dustry and EUA prices, } \mathrm{tCO}_{2} \text {. }\end{array}$ \\
\hline$I C_{p}^{\mathrm{C}}, I C_{p}^{\mathrm{R}}$ & Investment cost of technology $p$ or $r, € / \mathrm{MW}$. \\
\hline$L T_{y, y^{*}, p}^{\mathrm{C}}, L T_{y, y^{*}, r}^{\mathrm{R}}$ & $\begin{array}{l}\text { Availability in year } y \text { of an investment in technology } p \text { or } r \text { in } \\
\text { year } y^{*} \text {. }\end{array}$ \\
\hline
\end{tabular}




\begin{tabular}{|c|c|}
\hline$N^{\mathrm{EOM}}, N^{\mathrm{ETS}}$ & $\begin{array}{l}\text { Number of participants in the energy-only market and the ETS } \\
\text { auctions. }\end{array}$ \\
\hline$R T_{y}$ & Renewable energy target in the power sector in year $y$, MWh. \\
\hline$\overline{S_{y}}$ & $\begin{array}{l}\text { Supply of emission allowances in year } y \text { prior to the introduction } \\
\text { of the MSR, } \mathrm{tCO}_{2} \text {. }\end{array}$ \\
\hline$S V_{y, p}^{\mathrm{C}}, S V_{y, r}^{\mathrm{R}}$ & $\begin{array}{l}\text { Salvage value of an investment in technology } p \text { or } r \text { constructed } \\
\text { in year } y \text {. }\end{array}$ \\
\hline$V C_{p}$ & Variable operating cost of power plant technology $p, € / \mathrm{MW}$. \\
\hline$W_{d}$ & Weight of representative day $d$. \\
\hline$x_{y, m}^{\mathrm{MSR}}$ & Maximum outflow from the MSR in month $m$ of year $y, \mathrm{tCO}_{2}$. \\
\hline$\overline{x_{y, m}^{\mathrm{MSR}}}$ & Inflow to the MSR in month $m$ of year $y, \%$ of TNAC. \\
\hline \multicolumn{2}{|l|}{ Units } \\
\hline$k €$ & Thousands of Euros. \\
\hline $\mathrm{B} €$ & Billons of Euros. \\
\hline $\mathrm{MtCO}_{2}$ & Million tonnes of $\mathrm{CO}_{2}$. \\
\hline $\mathrm{GtCO}_{2}$ & Billion tonnes of $\mathrm{CO}_{2}$. \\
\hline
\end{tabular}




\section{Introduction}

The European Emission Trading System (EU ETS) is considered the flagship of EU climate policy. A binding, annually reducing carbon emission cap, enforced via a tradable EU emission allowance (EUA) system, has been put into place in order to provide a strong price signal for cost-effective greenhouse gas abatement in the European electric power sector, energy-intensive industry and the aviation sector. Because the EUA price had dropped to levels far below those needed to trigger long-term decarbonisation (Koch et al., 2014) (Fig. 1) due to a large surplus of allowances in the system (Table 1), the European institutions decided in 2015 to introduce a market stability reserve (MSR) by 2019 (European Union, 2015; Richstein et al., 2015). This MSR absorbs (part of) the excess EUAs in the market, currently unallocated EUAs and EUAs not auctioned in 2014-2016 (backloading) (Bel and Joseph, 2015; European Union, 2015). In 2018, the European Council decided to strengthen the ETS and MSR in three ways (European Union, 2018). First, from 2021 onward, the annual linear reduction factor (LRF) of the emissions cap increases from $1.74 \%$ to $2.2 \%{ }^{1}$ Second, from 2019 till 2023, the intake rate of the MSR doubles from $12 \%$ to $24 \%$. Third, from 2023 onward, the MSR can not contain more allowances than the total number of allowances auctioned during the previous year (European Union, 2018). In addition, the European Union recently adopted a binding renewable energy target of $32 \%$ of the final energy use by 2030 (European Parliament \& Council, 2018).

In the first year after the decision to strengthen the EU ETS, the EUA price tripled to a level above $20 € / \mathrm{tCO}_{2}$ and has stayed there since then. ${ }^{2}$ Looking at Figure 1, it seems that, after a long period of stagnant prices below $10 € / \mathrm{tCO}_{2}$, the strengthened MSR and increased LRF convinced market parties of the future scarcity of EUAs in the EU ETS.

In this paper we analyze the effects of the strengthened ETS, with specific attention for the cancellation of EUAs and the interaction with 2030 RES targets. In particular, we formulate a detailed European-wide equilibrium model that endogenously accounts for the reaction of the electric power sector, with a specific focus on short-term fuel switching and long-term investment in electricity generation capacity. This allows assessing the effect of the tightening of the emission cap on the EUA price, the required subsidies to meet the 2030 RES targets and the average wholesale electricity price, as well as investments in different electricity generation technologies. Furthermore, this allows accurately capturing the cost of meeting the emissions cap today and in the future, which affect the amount of EUAs cancelled by the MSR, thus the effective emissions cap. Indeed, the expectation of high abatement costs in the future provides an incentive for banking of EUAs, hence, increases the surplus today, the volume of allowances absorbed and cancelled by the MSR. The impact of this feedback effect depends on the relative difference between abatement costs today and in the future (Bruninx et al., 2019). In doing so, we bring together three strands of the literature.

\footnotetext{
${ }^{1}$ Although this increase in LRF was already proposed in 2015 (European Union, 2015), it was not included in the adopted legislative package describing the fist design of the MSR.

${ }^{2}$ Note that the EU Reference Scenario 2016 only expected this EUA price around the mid 2020s (Capros et al., 2016).
} 


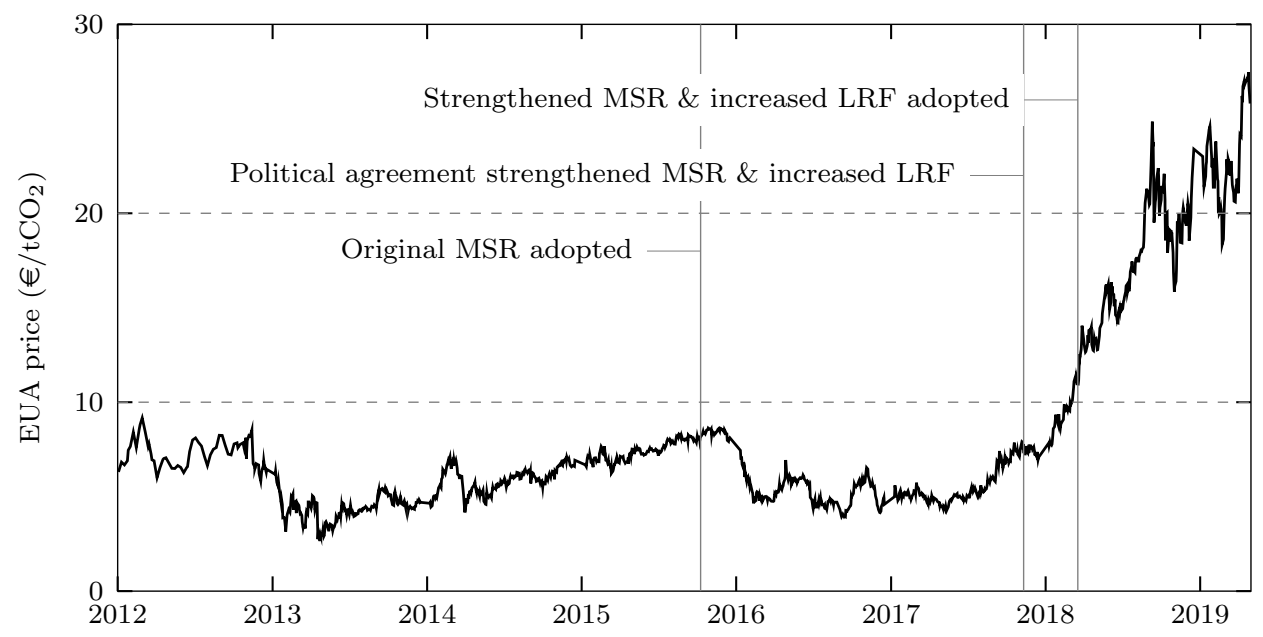

Figure 1. The EUA price during phase 3 of the EU ETS (EEX, Last accessed: August 1, 2019). Between 2012 and early 2018, the EUA price did not exceed $10 € / \mathrm{tCO}_{2}$, despite the adoption of the first design of the MSR in 2015. After the decision to commit to a strengthened MSR and increased LRF, EUA prices steadily increased, with peaks above $25 € / \mathrm{tCO}_{2}$.

The first strand of literature deals with the effect of EUA prices on $\mathrm{CO}_{2}$ emissions in the electricity sector. Several recent papers have simulated fuel switching decisions in response to carbon prices and their interaction with renewable policies (Delarue and D'haeseleer, 2008; Delarue and Van den Bergh, 2016; Pettersson et al., 2012; Weigt et al., 2013; Cullen and Mansur, 2017). These papers estimate that a switch from coal and oil to natural gas in the electric power sector lowers $\mathrm{CO}_{2}$ emissions by $2 \%$ (Pettersson et al., 2012) to $19 \%$ (Delarue and D'haeseleer, 2008; Weigt et al., 2013), depending on the EUA price and the studied period. This literature has, however, exclusively focused on the short-term operational effect of EUA prices, through merit-order switching of electricity generation technologies based on natural gas, oil and coal. Similar research focuses on the interaction between the subsidized deployment of renewables in the power sector and the EU ETS (De Jonghe et al., 2009; Van den Bergh et al., 2013; Delarue and Van den Bergh, 2016). For example, Van den Bergh et al. (2013) quantify the impact of RES deployment on the EUA price and $\mathrm{CO}_{2}$ emissions in the Western and Southern European electricity sector during the period from 2007 to 2010, following from an operational partial equilibrium model of the electricity sector. This study shows that the $\mathrm{CO}_{2}$ displacement from the electricity sector to other ETS sectors due to RES-E deployment can amount to more than $10 \%$ of historical $\mathrm{CO}_{2}$ emissions in the electricity sector. We contribute to the understanding of the interaction between RES targets and the EU ETS, including the strengthened MSR, by explicitly considering different power sector-specific RES targets for 2030 (Section 5).

A second strand in the scientific literature is concerned with the effect of EUA prices on long-term investments in carbon abatement measures under the EU ETS. Perino and Willner (2016) study intertemporal optimization by cost-minimizing firms, based on the dynamic optimization framework of cap-and-trade systems with banking introduced by Rubin (1996). This insightful continuous analytical model allows presenting the equilibrium paths of $\mathrm{CO}_{2}$ 
emissions, EUA prices, EUA surplus and the MSR, but it makes the simplifying assumption that the aggregate marginal abatement cost function is linear. The paper's quantitative results highly depend on the assumed functional form of the abatement cost function and the assumed parameter values. Our paper's equilibrium model-based approach allows for a more detailed analysis of the abatement options and costs in the electricity sector and energy-intensive industry over time. To the best of the authors' knowledge, our paper is the first one to study the effect of an ETS on long-term electricity generation investment using an equilibrium model, and, as a result, the first to assess the long-term qualitative effect of the strengthened MSR and increased LRF. ${ }^{3}$

Our long-term investment model assumes that individual risk-neutral agents make rational forward-looking decisions, based on their expectation of current and future EUA, renewable energy certificate (REC, see further) and energy prices. The equilibrium model allows obtaining the same equilibrium paths of emissions, prices and EUA surplus as those in continuous analytical models, but with the additional advantage that we model the long-term abatement cost function of the electricity sector (via dedicated investment models, electricity markets and RES targets) and the energy-intensive industry (via accurate, time-dependent abatement cost curves (Landis, 2015)) in detail, instead of making strong assumptions on its functional form. As outlined above and exposed in more detail by Bruninx et al. (2019), accurately capturing the costs of meeting the emissions cap today and in the future is critical in quantitative assessments of the impact of the MSR. We populate the model with parameters based on detailed data of the European electricity market. As the EUA price obviously fluctuates in response to changing commodity prices (Cullen and Mansur, 2017), macroeconomic evolutions (Bel and Joseph, 2015; Chevallier, 2009), technological developments and policy decisions (Van den Bergh et al., 2013; Delarue and Van den Bergh, 2016), we make assumptions about future operating costs (BP, 2017; ENTSO-E, 2018a), investment costs (International Energy Agency (IEA), 2015) and demand growth (European Commission, 2016). As EUAs can be banked indefinitely, we consider a 45 year period to study the impact of strengthening the ETS. In order to model the discrete if-then decisions of the MSR, we solve our equilibrium model using an ADMM-inspired (Alternating Direction Method of Multipliers) algorithm (Höschle et al., 2018; Boyd et al., 2011), which allows separating the agents' decision problems, determining the different market prices and the actions of the MSR (Section 3).

Leveraging the aforementioned model, our paper also adds to a third strand of literature that assesses the effect of an MSR in the EU ETS. Perino and Willner (2017) use the analytical model of Perino and Willner (2016) to assess the different proposals of the MSR, while Hepburn et al. (2016) discuss different options for reforming the MSR. Perino (2018) is the first to analyze the ultimately adopted strengthened MSR with cancellation. In this paper, we deliberately look beyond the short-term impact of the EU's MSR policy

\footnotetext{
${ }^{3}$ There exist a number of papers that endogenously deal with generation capacity investments under a carbon market with banking (Chappin et al., 2017; Richstein, 2015), but they leverage an agent-based electricity market simulation model instead of an equilibrium model and do not study the strengthened MSR. The results of such agent-based models are dependent on the assumptions on the rules governing the agents' decision problems, which complicates isolating the impact of the MSR.
} 
intervention, but we are also able to assess its effect in every year of the considered horizon. The analysis of this paper will show that the combination of the increased LRF and the strengthened MSR may indeed explain the observed abrupt change in EUA prices (Fig. 1). Assuming rational dynamic cost-minimizing firms, we observe a $303 \%$ increase in EUA prices under our reference assumptions: i.e., in 2019, prices increase from $6.8 € / \mathrm{tCO}_{2}$ under the policies before 2018 (initial MSR design, $1.74 \% \mathrm{LRF}$ ) to $27.4 € / \mathrm{tCO}_{2}$ under the current policies. Under a set of reference assumptions, cumulative $\mathrm{CO}_{2}$ emissions are $30.8 \mathrm{GtCO}_{2}$, hence $41 \%$ or $21.3 \mathrm{GtCO}_{2}$ below the cumulative cap before the strengthening $\left(52.2 \mathrm{GtCO}_{2}\right)$. Around $40 \%$ of this decrease $\left(8.3 \mathrm{GtCO}_{2}\right)$ is due to the increased linear reduction factor and $60 \%$ due to the cancellation policy $\left(13 \mathrm{GtCO}_{2}\right.$, which amounts to $29.7 \%$ of the cumulative cap assuming a LRF of $2.2 \%$ post 2020 ). We estimate that a total of 5.6 to $17.8 \mathrm{GtCO}_{2}$ of EUAs are taken out of the EU ETS in the period 2017-2061 via the cancellation provision of the MSR, depending on our assumptions on the availability and costs of certain technologies, demand growth and discount rates (Section 5.2). This wide range in possible cancellation volumes may be explained via the feedback effect discussed above (Bruninx et al., 2019). Indeed, the availability and costs of certain technologies, demand growth and discount rates affects the relative cost of meeting the emissions cap in the future, hence, has an influence on the profitability of banking allowances. This in turn affects the surplus today, the amount of allowances absorbed and cancelled by the MSR, and finally, the cumulative emissions. Note that in all these cases, the increased LRF leads to a $8.3 \mathrm{GtCO}_{2}$ emission reduction, in addition to the cancellation volumes mentioned above.

As a comparison, Perino and Willner (2017) estimate cancellation volumes at $1.7 \mathrm{GtCO}_{2}$, with TNAC (Total Number of Allowances in Circulation, a metric for the cumulative surplus between supply and demand for allowances, see Eq. (1) for a formal definition) levels below the $833 \mathrm{MtCO}_{2}$ threshold as of 2023, using a constant quadratic abatement cost curve from Landis (2015). Other authors report TNAC levels below $833 \mathrm{MtCO}_{2}$ at the latest by 2034 (Perino et al., 2019; Quemin and Trotignon, 2018; Beck and Kruse-Andersen, 2018). When we use the same quadratic abatement cost curve in our model to represent both the energyintensive industry and the power sector, we find a similar cancellation volume of $2.7 \mathrm{GtCO}_{2}$. Similarly, when we use a constant quadratic abatement cost curve of the same form as Perino and Willner (2017) and calibrate its parameter to reach the same EUA price in 2019 $\left(27.4 € / \mathrm{tCO}_{2}\right)$, we still observe a cancellation volume below $3 \mathrm{GtCO}_{2}$. The discrepancy with our central estimate $\left(13 \mathrm{GtCO}_{2}\right)$ is explained by the fact that the constant quadratic abatement cost curve fails to capture the relation between $\mathrm{CO}_{2}$ emissions and EUA prices at high abatement levels (Landis, 2015). Indeed, when we use the quartic polynomial of the exponential abatement (Eq. (4) in Landis (2015)) to describe the marginal abatement cost curves for both ETS-compliant sectors in our model, we find a cancellation volume of 10.9 $\mathrm{GtCO}_{2}$, close to our central estimate of $13 \mathrm{GtCO}_{2}$. By modeling the electricity sector in much detail, we find that the actual abatement cost curve is (i) more erratic and discontinuous and (ii) strongly increasing at high abatement levels, which can not be captured via quadratic abatement cost curves. As a consequence, we observe higher cancellation volumes, TNAC levels that remain longer above $833 \mathrm{MtCO}_{2}$ and higher EUA prices. These results stress the importance of the feedback effect (Bruninx et al., 2019), which impact is more pronounced as 
the relative difference between abatement costs today and in the future grows. Low-degree polynomials, such as the quadratic abatement cost curve employed by Perino and Willner (2017), fail to capture the increase in abatement costs at high abatement levels, hence, will lead to underestimations of the feedback effect and the cancellation volumes.

In summary, the added value of this paper is twofold. First, we put forward a mixed complementarity problem (MCP), capturing the equilibrium between electricity generation companies and the energy-intensive industry in energy, REC and EUA markets, considering the strengthened MSR and recently adopted RES-targets in 2030. Second, we provide an analysis of the long-term effect of the strengthened MSR, with a specific focus on the changes in the power sector. Results include, i.a., the investments in the power sector, the impact on electricity, REC and ETS prices, equilibrium emission trajectories and cancellation volumes. In a sensitivity analysis in Section 5, we illustrate that the effect of the strengthened MSR and increased LRF on, i.a., the cumulative, effective emissions cap and EUA prices is dependent on, i.a., the evolution of the costs of abatement options and other climate and energy policies, such as renewable energy targets and nuclear phase-out policies. Furthermore, we define a number of alternative policy scenarios, which allow identifying the relative importance of the different policy changes adopted in 2018 (i.e., the $2.2 \%$ LRF, the cancellation provision, the doubling of the intake and outflow rates) and RES targets for the power sector.

The remainder of this paper is structured as follows. Section 2 dissects the working principles of the MSR and the EU ETS. Second, the methodology, mathematical formulation of the model and the ADMM algorithm are introduced in Section 3. The data and assumptions required for the numerical simulations are presented in Section 4. The results, both for our reference case and the sensitivity analyses, are discussed in Section 5. Before moving to concluding remarks (Section 7), we discuss the policy implications of our work in Section 6 .

\section{The European Emission Trading System and the Market Stability Reserve}

To elevate EUA prices to meaningful levels, in 2015, the Council and the European Parliament took the decision to establish a Market Stability Reserve (MSR) (European Union, 2015). As outlined above, this legislative package was amended in 2018 (European Union, 2018), (i) strengthening the MSR via temporarily increased intake and outflow rates and the cancellation of allowances post 2023 and (ii) increasing the linear reduction factor as of 2021. The new rules governing the EU ETS are summarized in Table 2. In the period 2013-2020, the cap on emissions is reduced by a linear reduction factor equal to $1.74 \%$ of the 2010 cap (Table 2). This means that in 2021, greenhouse gas emissions from the covered sectors will be $21 \%$ lower than in 2005 . As of 2021 , the cap on emissions will annually be reduced by a linear reduction factor equal to $2.2 \%$ of the 2010 cap (Table 2), such that $\mathrm{CO}_{2}$ emissions will be $43 \%$ lower in 2030 than in 2005 (European Union, 2018).

Starting in 2019 and as long as the total number of allowances in circulation (TNAC) is above $833 \mathrm{MtCO}_{2}$, the MSR will absorb part of the EUAs in circulation. The TNAC, which is a measure for the surplus of EUAs in the system, at the end of year $y$ is defined as 
(European Union, 2015; European Commission, 2017):

$$
\begin{aligned}
\operatorname{TNAC}_{y}= & \sum_{y^{*}=2008}^{y}\left(\text { Supply }_{y^{*}}-(\text { Demand and voluntary cancellation })_{y^{*}}\right) \\
& - \text { Allowances in the } \mathrm{MSR}_{y}
\end{aligned}
$$

According to European Commission (2018), the TNAC was 1,655 $\mathrm{MtCO}_{2}$ at the end of 2018. Table 1 shows that this surplus has decreased by $39 \mathrm{MtCO}_{2}$ from 2016 to 2017 and has stayed constant from 2017 to 2018. Note furthermore that the supply of allowances in 2018 was below the emissions cap lowering the surplus. ${ }^{4}$ This table also gives a more detailed breakdown of the supply and demand of allowances from 2008 till 2018.

The exact number of allowances absorbed by the MSR in each year depends on the TNAC in previous years: as long as the TNAC is above $833 \mathrm{MtCO}_{2}, 8 \%$ of it is transferred to the MSR in the next year and $16 \%$ in two years (Table 2). As of 2024, these percentages are halved to $4 \%$ and $8 \%$. Following Table 1, this means that in 2019, 0.16 $\cdot 1,655$ million + $0.08 \cdot 1,655$ million $=397$ million allowances will be absorbed by the MSR. This mechanism will effectively decrease the TNAC. Once the TNAC in the previous years drops below 400 $\mathrm{MtCO}_{2}$, the MSR will release $200 \mathrm{MtCO}_{2}$ (prior to 2024) or $100 \mathrm{MtCO}_{2}$ (as of 2024) to the market (Table 2). If the MSR does not contain $200 \mathrm{MtCO}_{2}$ (before 2024) or $100 \mathrm{MtCO}_{2}$ of EUAs, all EUAs in the MSR are released.

From 2023, the MSR can not contain more allowances than the total number of allowances auctioned during the previous year ${ }^{5,6}$. This includes allowances which are to be auctioned at a later point in time because of their placement in the MSR. ${ }^{7}$

\footnotetext{
${ }^{4}$ The difference between the annual emissions cap (i.e., the predetermined ceiling on emissions, based on the negotiated cap for the year 2013 and annually decreasing with the linear reduction factor) and the effective annual supply of allowances (i.e., the sum of allocated and auctioned allowances in a given year) may persist for a number of reasons. First, not all free allocations are handed to industry, because some facilities have either gone out of business or have cut their production sufficiently as such that they fall below a threshold and are not entitled to their intended allocation (partial cessation). Second, not all the Article 10C allocations have been handed out. These are the allowances that are freely allocated for modernization of the power sector in a number of European countries. Third, new entrance reserve (NER) allowances were monetized in front-loading selling in 2012-2013, so are not spread evenly throughout Phase 3 (2013-2020). Also, not all NER allowances have been allocated, due to a lack of new entrants, and therefore some will go unused at the end of Phase 3. Fourth, the auction volumes are not necessary tied to the exact dates. Last, the MSR may reduce or increase the supply of allowances w.r.t. the cap in a given year.

5 "Unless otherwise decided in the first review carried out in accordance with Article 3, from 2023 allowances held in the reserve above the total number of allowances auctioned during the previous year shall no longer be valid." (European Union, 2018).

6 "From 2021 onwards, and without prejudice to a possible reduction pursuant to Article 10a(5a), the share of allowances to be auctioned shall be $57 \%$." (European Union, 2018).

7 "The number of auctioned allowances is made up of allowances auctioned on behalf of Member States, including allowances set aside for new entrants but not allocated, allowances for modernizing electricity generation in some Member States and allowances which are to be auctioned at a later point in time because of their placement in the market stability reserve established by Decision (EU) 2015/1814 of the European Parliament and of the Council." (European Union, 2018).
} 
In addition to the gradual absorption of EUAs, another 900 million back-loaded and an estimated 700 million unallocated allowances will be absorbed by the MSR in 2019 and 2021 (European Union, 2015) (Table 2). Note that these allowances must also be accounted for in the supply of allowances in the calculation of the TNAC (Table 1), although it is currently unclear if and how the European Commission intends to do so. ${ }^{8}$ If not properly accounted for, placing these allowances in the MSR would trigger a significant decrease of the TNAC at the end of 2019 and 2020 (see Eq. (1)). Indeed, the backloaded and unallocated allowances combined amount to $1,600 \mathrm{MtCO}_{2}$, which is close to the TNAC of $1,655 \mathrm{MtCO}_{2}$ at the end of 2018. Consequently, the TNAC would be reduced to values well below $833 \mathrm{MtCO}_{2}$, hence, lead to lower or zero intake rates in the period 2021-2024 and, consequently, lower cancellation volumes.

An aspect of the cancellation of allowances that has sparked some debate is its impact on the 'waterbed effect' (i.e., individual changes in $\mathrm{CO}_{2}$ emissions have no aggregate effect, as the cap is fixed (Perino, 2018)). As a change of the TNAC affects the number of allowances absorbed and cancelled, the waterbed is said to be temporarily punctured (Perino, 2018). As a result, abatement and emissions by market participants have an effect on the number of allowances canceled. However, because of the gradual absorption of EUAs by the MSR, an increase of the TNAC (e.g., because of decreased electricity consumption, decreased economic activity or increased abatement) does not lead to a one-to-one increase of the holidings of the MSR. ${ }^{10}$ Only the following share will be absorbed and cancelled by the MSR (Perino, 2018):

$$
1-(1-0.24)^{n} \cdot(1-0.12)^{m}
$$

where $n$ and $m$ are the number of years between the time of increasing the TNAC by a single allowance and the year the MSR stops absorbing EUAs (i.e., when the TNAC falls below

8 "The Commission shall publish the total number of allowances in circulation each year, by 15 May of the subsequent year. The total number of allowances in circulation in a given year shall be the cumulative number of allowances issued in the period since 1 January 2008, including the number issued pursuant to Article 13(2) of Directive 2003/87/EC in that period and entitlements to use international credits exercised by installations under the EU ETS in respect of emissions up to 31 December of that given year, minus the cumulative tonnes of verified emissions from installations under the EU ETS between 1 January 2008 and 31 December of that same given year, any allowances cancelled in accordance with Article 12(4) of Directive 2003/87/EC and the number of allowances in the reserve. No account shall be taken of emissions during the three-year period starting in 2005 and ending in 2007 and allowances issued in respect of those emissions." (European Union, 2015).

${ }^{9}$ New Entrants Reserve, which contains the revenues of 300 million EUAs, to be used for subsidizing installations of innovative renewable energy technology and carbon capture and storage (CCS) (European Commission, 2017).

${ }^{10}$ Note that aviation is currently excluded from the calculation of the TNAC. Increased emissions from the aviation sector has therefore no effect on the number of allowances placed in the MSR and, consequently, being canceled, but it will effectively decrease the surplus of allowances. Between 2012 and 2018, the inclusion of intra-European flights in the EU ETS has delivered an additional reduction of 100 million allowances, because only around 38 million allowances has been issued yearly, while verified $\mathrm{CO}_{2}$ emissions from aviation activities carried out between airports in the EEA have increased from $53.5 \mathrm{MtCO}_{2}$ in 2013 to $64.2 \mathrm{MtCO}_{2}$ in 2017. As a result, the European Commission will at some point in the future have to address the gap between the defined TNAC (see Eq. (1)) and the actual surplus of allowances. 
Table 1. Supply and demand of EU ETS allowances as of 2013 in $\mathrm{MtCO}_{2}$ (European Commission, 2017, 2018, 2019). A significant part of the surplus resulted from the banking of allowances from the 2008-2012 period, during which, i.a., the 2008-2009 economic downturn depressed emissions, creating an excess of EAUs. The difference between the cap and effective supply of EUAs, refered to as unallocated allowances, will be placed in the MSR after the third phase of the EU ETS (see below). Note furthermore that the supply of allowances in $2018\left(1,690 \mathrm{MtCO}_{2}\right)$ is below the emissions cap $\left(1,892 \mathrm{MtCO}_{2}\right)$ (excluding aviation).

\begin{tabular}{lccccc}
\hline \hline & 2016 & 2017 & 2018 & $2017-2016$ & $2018-2017$ \\
\hline Supply & & & & & \\
\hline (a) Banking from 2008-2012 & 1,750 & 1,750 & 1,750 & 0 & 0 \\
(b) Allowances allocated for free & 3,601 & 4,403 & 5,162 & 802 & 759 \\
(c) Allowances auctioned & 2,774 & 3,726 & 4,641 & 951 & 915 \\
(d) NER300 programme & 300 & 300 & 300 & 0 & 0 \\
(e) International credit entitlements & 409 & 419 & 434 & 10 & 15 \\
Sum supply & 8,833 & 10,597 & 12,287 & 1,764 & 1,690 \\
\hline Demand & & & & & \\
\hline (a) Verified emissions & 7,139 & 8,942 & 10,632 & 1,803 & 1,690 \\
(b) Allowances canceled & 0.19 & 0.28 & 0.32 & 0.09 & 0.04 \\
(c) Allowances in the MSR & 0 & 0 & 0 & 0 & 0 \\
Sum demand & 7,140 & 8,943 & 10,632 & 1,803 & 1,690 \\
\hline Surplus of allowances (TNAC) & 1,694 & 1,655 & 1,655 & -39 & 0 \\
\hline \hline
\end{tabular}

the $833 \mathrm{MtCO}_{2}$ threshold), with intake rates of $24 \%$ and $12 \%$ (Perino, 2018). For example, if the TNAC falls below the threshold in 2023, a $1 \mathrm{tCO}_{2}$ abatement in 2019 will decrease cumulative emissions by $0.67 \mathrm{tCO}_{2}\left(=1-(1-0.24)^{4}\right)$, while a $1 \mathrm{tCO}_{2}$ abatement in 2022 will decrease the cumulative emissions by only $0.24 \mathrm{tCO}_{2}\left(=1-(1-0.24)^{1}\right)$.

This temporary puncture of the waterbed increases the relevance of complementary climate policies - such as targets for renewable energy production or energy efficiency and unilateral policies (Perino et al., 2019) - as they affect the TNAC, hence, the actions of the MSR. In this regard, it is worth mentioning the recently adopted 2030 RES target of $32 \%$ of the final energy use (European Parliament \& Council, 2018). ${ }^{11}$ To facilitate cost-effective compliance with these targets, the European Commission foresees extensive collaborative efforts between member states, e.g., via statistical transfers, joint projects and joint support schemes. As targets per country and per sector are currently undecided, we will assume a uniform 32\% target across sectors in our reference scenario and perform sensitivity analyses on this target. Note, however, that (i) the current national renewable energy actions plans of the Member States envision a renewable energy share of 34\% in the power sector in 2020 (Elia, 2017) and (ii) the European Commission does not allow Member States to decrease their share of renewable energy w.r.t. their 2020 targets after 2020 (European Parliament

\footnotetext{
11 "Member States shall collectively ensure that the share of energy from renewable sources in the Union's gross final consumption of energy in 2030 is at least 32 \%.” (European Parliament \& Council, 2018).
} 
\& Council, 2009). Hence, depending on the demand growth and the target in 2030, the 2020 or 2030 target may be binding. To ensure compliance with the most stringent target, we assume a European Renewable Certificate (REC) system, in line with the foreseen joint support schemes (European Parliament \& Council, 2018). The resulting REC prices and associated out-of-market payments must be interpreted as minimum subsidy costs to meet the renewable energy target in the power sector. Because we do not model any national or regional subsidies for specific renewable technologies, the REC subsidies will incentivize investment in the renewable technology that generates electricity at the lowest cost per MWh. Additional subsidies for a specific renewable technology will change our estimated REC prices and generation share of the considered renewable technologies. However, if the renewable target in the power sector is binding, this will not affect the overall RES share.

In the next section, we introduce the equilibrium model used to study the interaction between the power sector and the energy-intensive industry in the energy-only electricity market, renewable energy targets and the ETS with the increased LRF and strengthened MSR. By modeling both dispatch and investment decisions under prevailing electricity, REC and EUA prices, this paper quantifies the total abatement in the electricity sector due to both short-term merit-order fuel switching and long-term investment in electricity generation technologies over time. This model allows calculating, i.a., equilibrium emission trajectories for the power sector and energy-intensive industry under the associated equilibrium EUA prices. 


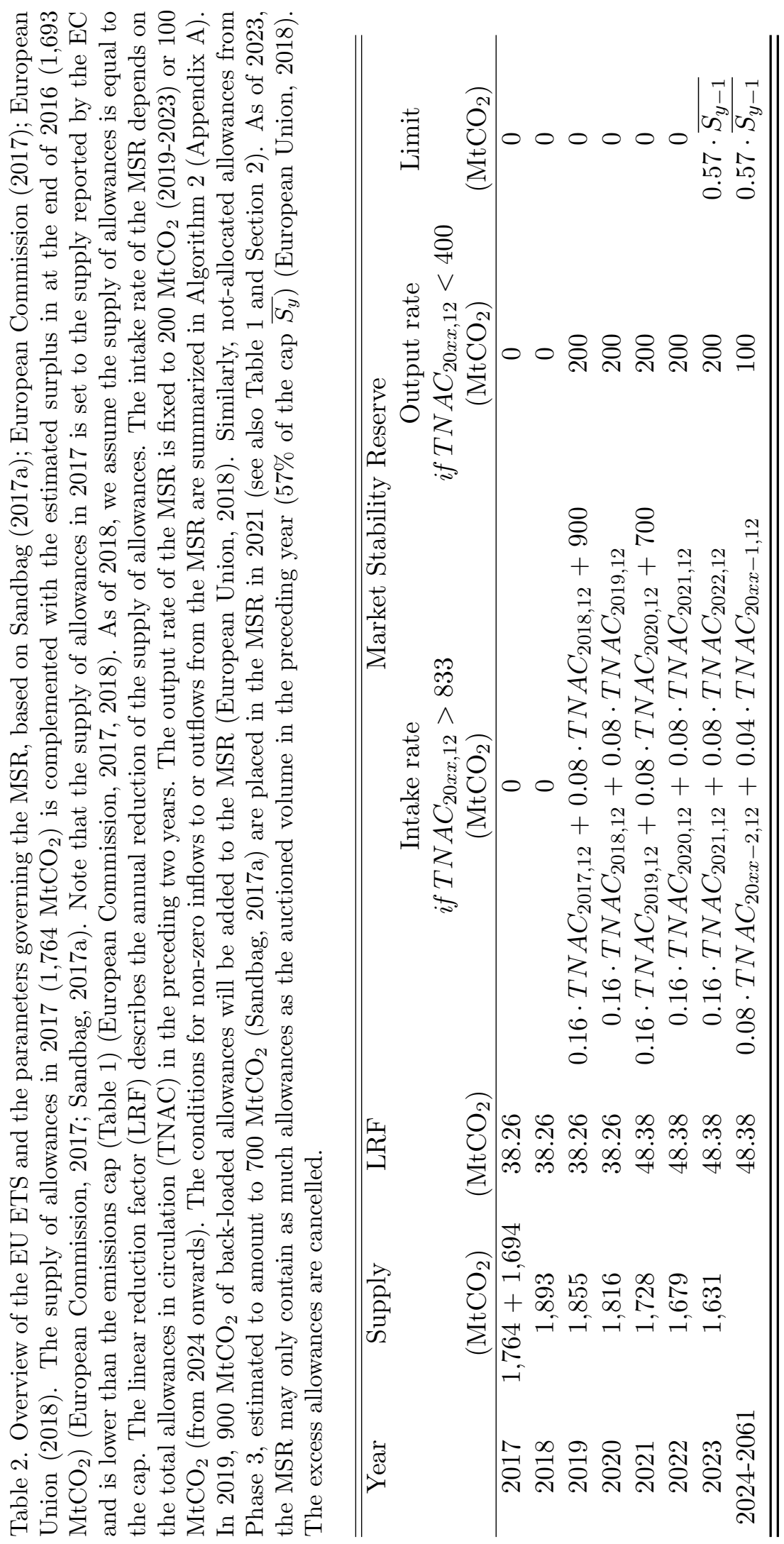




\section{Methodology}

The equilibrium between $\mathrm{CO}_{2}$ abatement actions in industry, investment and operational decisions in the electric power sector, the wholesale electricity market, RES targets and the EU ETS is formulated as a large-scale Mixed Complementarity Problem (MCP). The energyintensive industry minimizes the cost of procuring EUAs to offset their $\mathrm{CO}_{2}$ emissions. The annual $\mathrm{CO}_{2}$ emissions of the energy-intensive industry are determined endogenously as a function of the EUA price. Conventional electricity generation companies invest in new power plants if their expected profit in the wholesale market covers their investment and operating costs, including their expenses for EUAs under the EU ETS. Renewable electricity generation companies receive RECs, in addition to revenues from the energyonly electricity market, to ensure compliance with the 2020 and 2030 RES targets. As we assume no barriers to investment (free entry) and a perfectly competitive wholesale market, investment will occur until expected profits associated with new generation capacity are zero. The wholesale electricity market, a REC system and the EU ETS are enforced as coupling constraints in the large-scale MCP. The demand for electricity is imposed exogenously on the electricity market clearing. The EU ETS system is characterized by an annual amount of EUAs released, the current excess and the MSR. The MCP is solved using ADMM, inspired by Höschle et al. (2018). In what follows, we subsequently introduce the agents, their interactions and a non-exhaustive list of assumptions (Section 3.1). Second, we provide the mathematical formation of the optimization problem solved by each of the agents and the coupling constraints (Section 3.2). Before moving to the simulation results, the solution strategy is introduced.

\subsection{Description of the Mixed Complementarity Problem}

\subsubsection{Agents, objectives $\&$ coupling constraints}

The power sector is represented by a set of agents, each responsible for the operation of and investment in a specific renewable or conventional generation technology. The energyintensive industry is represented through the relation between $\mathrm{CO}_{2}$ emissions and EUA prices obtained from a general equilibrium model by Landis (2015). The $\mathrm{CO}_{2}$ emissions of the energy-intensive industry are capped to the reported 2017 emissions (Sandbag, 2017a). The demand for goods and services produced by the energy-intensive industry is not considered explicitly. The relationship between $\mathrm{CO}_{2}$-emissions and EUA prices proposed by Landis (2015) should, however, be interpreted as a the marginal abatement cost function of an energy-intensive sector where both industries and consumers may respond to higher allowance prices by adopting energy efficiency measures and decreasing the consumption of more polluting and, thus, expensive goods and services. Generating companies offer their capacity at long-run marginal generation cost, i.e., including capacity costs for to-bebuilt installations, in the energy-only market (no strategic behavior) and compete with the energy-intensive industry for EUAs on the EU ETS auctions. We enforce the compliance with the RES target by imposing a REC system. The RECs must be considered as the minimal mark-up on top of the energy-only price that ensures the economic viability of investments in RES-based generation required to meet the RES targets. Prices are obtained as 
the Lagrangian multipliers of the coupling constraints enforcing the balance in each market, assuming an inelastic demand (energy-only market and REC system) or an inelastic supply (EU ETS, corrected for the actions of the MSR).

\subsubsection{Interactions}

All agents base their investment decisions solely on the electricity, REC and EUA price. None of their decision variables are communicated to other market participants. Generating companies provide the amount of electricity they are willing to generate at each time step to the energy-only market and submit a demand for EUAs to the ETS auction. Simultaneously, RES-based generation companies provide the annual output of their currently installed and to-be-build power plants to the REC market. The energy-intensive industry decides on the quantity of EUAs they need to procure in each year.

\subsubsection{Assumptions}

In order to isolate the impact of the policy measure, we assume that all agents act rational, price-taking and risk-neutral, which is common practice in long-term investment models (Poncelet et al., 2020; Hirth, 2013; Pfenninger et al., 2014). They have perfect foresight on EUA, REC and energy prices on perfectly competitive markets, allowing intertemporal arbitrage, and do not perceive any barriers to entry, as in, i.a., Perino and Willner (2016, 2017) and Kollenberg and Taschini (2016).

In the electricity market clearing, the transmission system is not considered, nor are interconnections of the European power system to, e.g., Russia and Tunesia. For conventional, thermal electricity generation, only fuel costs are considered - other operating and maintenance costs are neglected. The dispatch schedules resulting from the energy-only electricity are assumed to be the actual generation schedules, hence the emissions may be directly obtained from the result of the market clearing. The electricity market is cleared with an hourly resolution, assuming an inelastic demand. The demand for electrical energy and the availability of renewable energy sources in each calendar year is represented via a set of four representative days, optimally selected from load, solar and wind power timeseries of calender year 2017 (ENTSO-E, 2018b) via the method of Poncelet et al. (2017). Since the relation between abatement efforts in the energy-intensive industry and electrification is fundamentally uncertain (McKinsey \& Company, 2018) and dependent on the elasticity of fuel substitution, we do not link electricity demand growth to emission reductions in the energy-intensive industry. Similarly, electrification in other sectors and the electricity demand from novel technologies is exogenously imposed on the model by considering a demand growth rate and perform a sensitivity analysis w.r.t. this parameter.

Dynamic power plant constraints, operating reserves, ... are not considered in the model. As such, one may overestimate the contribution of, e.g., less flexible technologies, such as current coal- and lignite-fired units. However, this effect may be partially compensated by the fact that we do not consider, e.g., demand side flexibility or energy storage, which may absorb the variability and short-term uncertainty associated with RES-based electricity generation. Similarly, the single profile representation of RES availability and its limited 
temporal resolution may lead to technology biases. However, we believe that this may result in shifts between technologies, but does not significantly impacts $\mathrm{CO}_{2}$ emissions.

The EUA auctions are executed annually, motivated by the yearly obligation of the market participants to surrender EUAs to cover their emissions and the assumption of perfect foresight across the model horizon. This allows perfect price arbitrage within the year, given the bankable nature of EUAs, levelling out price differences. We assume generating companies and the energy-intensive industry bank allowances themselves, i.e., we do not consider financial institutes that would act as intermediaries.

Similarly, the price of REC is calculated annually. The REC are awarded on a per MWh basis and spread-out from 2020 to the end of the model horizon, to ensure (i) the renewable energy targets are met in 2020 and (ii) the share of renewable energy does not decrease below the 2020 target after 2020. We assume a RES target in each year, starting from the 2020 RES target (34\% of the electricity demand in 2020) (Elia, 2017) and linearly increasing to the RES target in 2030 (in our reference policy scenario, $32 \%$ of the electricity demand in 2030). If the 2020 RES target is more stringent than the 2030 target (e.g., due to low demand growth), we enforce the 2020 target in absolute terms (i.e., in GWh) in 2030. Post 2030, the 2030 RES target is considered as a lower bound, i.e., the energy output from RES in the power sector must remain at least equal to the 2030 RES target in absolute terms. Only to-be-built capacity is eligible for REC, as we assume current RES-based capacity is either paid-for or covered under other out-of-market support schemes. Note, however, that the output of legacy RES capacity is accounted for in the calculation of the gap between the annual RES output and the target in each year.

\subsection{Mathematical model}

\subsubsection{Profit-maximizing conventional generating company $p$}

The expected profit of each conventional generating company $p$ (set $\mathcal{P}$ ) is calculated as the discounted sum of the difference between the energy-only market price $\lambda_{y, d, h}^{\mathrm{EOM}}$ and the variable generation cost $V C_{p}^{\mathrm{C}}$ multiplied with the generated energy $g_{y, d, h, p}^{\mathrm{C}}$ at each time step $h$ in a number of representative days $d$, weighted by $W_{d}$. This expected profit must cover the investment costs $I C_{p}^{\mathrm{C}} \cdot c p_{y, p}^{\mathrm{C}}$, corrected for the salvage value $S V_{y, p}^{\mathrm{C}}$ of the investment at the end of the model horizon, and the cost of procuring EUAs $\lambda_{y}^{\text {ETS }} \cdot b_{y, p}^{\mathrm{C}}$, with $\lambda_{y}^{\mathrm{ETS}}$ the price of an EUA. For each conventional generating company $p \in \mathcal{P}$, we solve the following optimization problem:

$$
\underset{g_{y, h, p}^{\mathrm{C}}, b_{y, p}^{\mathrm{C}}, c p_{y, p}^{\mathrm{C}}}{\operatorname{Max}} \sum_{y \in \mathcal{Y}} A_{y} \cdot\left[\sum_{d \in \mathcal{D}} W_{d} \cdot \sum_{h \in \mathcal{H}}\left(\lambda_{y, d, h}^{\mathrm{EOM}}-V C_{p}^{\mathrm{C}}\right) \cdot g_{y, d, h, p}^{\mathrm{C}}-\left(1-S V_{y, p}^{\mathrm{C}}\right) \cdot I C_{p}^{\mathrm{C}} \cdot c p_{y, p}^{\mathrm{C}}-\lambda_{y}^{\mathrm{ETS}} \cdot b_{y, p}^{\mathrm{C}}\right]
$$


subject to

$$
\begin{aligned}
& \forall y \in \mathcal{Y}, d \in \mathcal{D}, h \in \mathcal{H}, p \in \mathcal{P}: g_{y, d, h, p}^{\mathrm{C}} \leq \sum_{y^{*}=1}^{y} L T_{y, y^{*}, p}^{\mathrm{C}} \cdot c p_{y *, p}^{\mathrm{C}}+\overline{C P_{y, p}^{\mathrm{C}}} \\
& \forall y \in \mathcal{Y}, p \in \mathcal{P}: \sum_{y^{*}=1}^{y} \sum_{d \in \mathcal{D}} W_{d} \cdot \sum_{h \in \mathcal{H}} C I_{p}^{\mathrm{C}} \cdot g_{y^{*}, d, h, p}^{\mathrm{C}} \leq \sum_{y^{*}=1}^{y} b_{y^{*}, p}^{\mathrm{C}} \\
& \forall y \in \mathcal{Y}, d \in \mathcal{D}, h \in \mathcal{H}, p \in \mathcal{P}: g_{y, h, p}^{\mathrm{C}}, b_{y, p}^{\mathrm{C}}, c p_{y, p}^{\mathrm{C}} \geq 0
\end{aligned}
$$

Constraint (4) limits the output of technology $p$ to the to-be-installed capacity $\sum_{y^{*}=1}^{y} L T_{y, y^{*}, p}^{\mathrm{C}}$. $c p_{y *, p}^{\mathrm{C}}$, accounting for its lifetime and the lead time on the investment through parameter $L T_{y, y^{*}, p}^{\mathrm{C}}$, and the legacy capacity $\overline{C P_{y, p}^{\mathrm{C}}}$. The annual $\mathrm{CO}_{2}$ emissions associated with this technology are calculated based on its carbon intensity $C I_{p}^{\mathrm{C}}$ and should be offset by procured EUAs $b_{y, p}^{\mathrm{C}}$ up to that year $y($ Eq. (5)).

\subsubsection{Profit-maximizing renewable generating company $r$}

Renewable generating companies invest in additional capacity $c p_{y, r}^{\mathrm{R}}$ of type $r$ until expected profits, i.e., the difference between (i) profits from the energy-only market on a number of representative days $\sum_{y \in \mathcal{Y}} \sum_{d \in \mathcal{D}} \sum_{h \in \mathcal{H}} A_{y} \cdot W_{d} \cdot \lambda_{y, d, h}^{\mathrm{EOM}} \cdot g_{y, d, h, r}^{\mathrm{R}}$ and REC $\sum_{y \in \mathcal{Y}} A_{y} \cdot \lambda_{y}^{\mathrm{REC}}$. $g_{y, r}^{\mathrm{R}, \mathrm{NB}}$, with $\lambda_{y}^{\mathrm{REC}}$ the REC price, and (ii) the investment $\operatorname{costs} \sum_{y \in \mathcal{Y}} A_{y} \cdot\left(1-S V_{y, r}^{\mathrm{R}}\right) \cdot I C_{r}^{\mathrm{R}} \cdot c p_{y, r}^{\mathrm{R}}$, are zero:

$$
\underset{g_{y, d, h, r}^{\mathrm{R}}, g_{y, r}^{\mathrm{R}, \mathrm{NB}}, c p_{y, r}^{\mathrm{R}}}{\mathrm{Max}_{y \in \mathcal{Y}}} \sum_{y \in \mathcal{H}} A_{y} \cdot\left[\sum_{d \in \mathcal{D}} W_{d} \cdot \sum_{h \in \mathcal{H}} \lambda_{y, d, h}^{\mathrm{EOM}} \cdot g_{y, d, h, r}^{\mathrm{R}}+\lambda_{y}^{\mathrm{REC}} \cdot g_{y, r}^{\mathrm{R}, \mathrm{NB}}-\left(1-S V_{y, r}^{\mathrm{R}}\right) \cdot I C_{r}^{\mathrm{R}} \cdot c p_{y, r}^{\mathrm{R}}\right]
$$

subject to

$$
\begin{aligned}
& \forall y \in \mathcal{Y}, d \in \mathcal{D}, h \in \mathcal{H}, r \in \mathcal{R}: g_{y, d, h, r}^{\mathrm{R}} \leq A V_{d, h, r} \cdot\left(\sum_{y^{*}=1}^{y} L T_{y, y^{*}, r}^{\mathrm{R}} \cdot c p_{y^{*}, r}^{\mathrm{R}}+\overline{C P_{y, r}}\right) \\
& \forall y \in \mathcal{Y}, \forall r \in \mathcal{R}: g_{y, r}^{\mathrm{R}, \mathrm{NB}} \leq \sum_{d \in \mathcal{D}} W_{d} \cdot \sum_{h \in \mathcal{H}} A V_{d, h, r} \cdot \sum_{y^{*}=1}^{y} L T_{y, y^{*}, r}^{\mathrm{R}} \cdot c p_{y *, r}^{\mathrm{R}} \\
& \forall y \in \mathcal{Y}, d \in \mathcal{D}, h \in \mathcal{H}, r \in \mathcal{R}: g_{y, d, h, r}^{\mathrm{R}}, g_{y, r}^{\mathrm{R}, \mathrm{NB}}, c p_{y, r}^{\mathrm{R}} \geq 0
\end{aligned}
$$

Note that (i) variable generation costs are assumed to be zero; (ii) $\mathrm{CO}_{2}$ emissions from RESbased generation are not considered; (iii) the variable nature of some forms of renewable generation is captured via the availability profile $A V_{d, h, r}$ and (iv) REC are only awarded to newly built capacity, based on their annual output $g_{y, r}^{\mathrm{R}, \mathrm{NB}}$.

\subsubsection{Cost-minimizing industry}

To represent the impact of the energy-intensive industry on the demand for EUAs, we consider the relationships between the EUA price $\lambda_{y}^{E T S}$ and emissions $e_{y}^{\mathrm{I}}$ obtained by Landis 
(2015), here summarized as $e_{y}^{\mathrm{I}}=\mathcal{F}_{y}\left(\lambda_{y}^{E T S}\right)$. The energy-intensive industry minimizes the procurement cost of the required EUAs $b_{y}^{\mathrm{I}}$ to cover their emissions $e_{y}^{\mathrm{I}}$ :

$$
\operatorname{Min}_{e_{y}^{\mathrm{I}}, b_{y}^{\mathrm{I}}} \sum_{y \in \mathcal{Y}} A_{y} \cdot \lambda_{y}^{E T S} \cdot b_{y}^{\mathrm{I}}
$$

subject to

$$
\begin{aligned}
& \forall y \in \mathcal{Y}: \sum_{y^{*}=1}^{y} b_{y^{*}}^{\mathrm{I}} \geq \sum_{y^{*}=1}^{y} e_{y^{*}}^{\mathrm{I}} \\
& \forall y \in \mathcal{Y}: e_{y}^{\mathrm{I}}=\mathcal{F}_{y}\left(\lambda_{y}^{E T S}\right) \\
& \forall y \in \mathcal{Y}: b_{y}^{\mathrm{I}} \geq 0
\end{aligned}
$$

Constraint (12) ensures that the energy-intensive industry procures sufficient allowances $b_{y}^{\mathrm{I}}$ to offset its $\mathrm{CO}_{2}$ emissions $e_{y}^{\mathrm{I}}$, calculated via the relation between allowance prices and emissions $\mathcal{F}_{y}\left(\lambda_{y}^{E T S}\right)($ Eq. (13)).

\subsubsection{Energy-only market, REC and ETS auctions as coupling constraints}

The decision problems of the agents above are linked trough three coupling constraints, representing the equilibrium in the energy-only market (EOM) for electricity, the ETS and REC auctions:

$$
\begin{array}{lr}
\forall y \in \mathcal{Y}, d \in \mathcal{D}, h \in \mathcal{H}: & \sum_{p \in \mathcal{P}} g_{y, d, h, p}^{\mathrm{C}}+\sum_{r \in \mathcal{R}} g_{y, d, h, r}^{\mathrm{R}}-D_{y, d, h} \geq 0 \quad\left(\lambda_{y, d, h}^{E O M}\right) \\
\forall y \in \mathcal{Y}: & S_{y}-\sum_{p \in \mathcal{P}} b_{y, p}^{\mathrm{C}}-b_{y}^{\mathrm{I}} \geq 0 \quad\left(\lambda_{y}^{E T S}\right) \\
\forall y \in \mathcal{Y}: & \sum_{r \in \mathcal{R}} \sum_{d \in \mathcal{D}} W_{d} \sum_{h \in \mathcal{H}} g_{y, d, h, r}^{\mathrm{R}}-R T_{y} \geq 0 \quad\left(\lambda_{y}^{R E C}\right)
\end{array}
$$

with $D_{y, d, h}$ the demand for electricity in each hour $h$ of representative day $d$ in year $y, S_{y}$ the supply of allowances and $R T_{y}$ the renewable energy target in the power sector.

The dual variables associated with these constraints are indicated between parentheses and may be interpreted as the prices in the EOM, ETS and REC auctions that ensure that each agent's strategy coincides with its long-run equilibrium strategy. In other words, presented with these prices, no agent has an incentive to change its strategy. Note that the supply of allowances $S_{y}$ is the net supply of EUAs, corrected for the actions of the MSR. The MSR actions are imposed on the price update steps of the ADMM algorithm, which enforces the coupling constraints (Eq. (15)-(17)), as discussed below.

\subsection{Solving the MCP using ADMM}

In order to calculate the equilibrium between conventional generating companies, renewable generating companies and the energy-intensive industry defined by Eq. (3)-(17), we leverage an ADMM-based algorithm inspired by Höschle et al. (2017); Höschle (2018). In 


\footnotetext{
${ }^{12}$ Penalty terms are added to the objectives of the agents based on the augmented Lagrangian. These penalty terms, which reduce to zero upon convergence of the algorithm, avoid excessive oscillatory behavior and overreactions to small price differences. For more details, the reader is referred to Appendix A.

${ }^{13}$ For details on the stopping criterion and convergence metrics, we refer the interested reader to Appendix A and Höschle (2018).
} 
central reference scenario, designed to reflect current policies. The design and current state of the EU ETS system are based on European Commission $(2017,2018,2015)$ and European Union (2018) (Table 2). In Section 5.2, we discuss which assumptions below are changed in our alternative policy scenarios and sensitivity analyses.

The currently installed power plant capacity is based on the most recent data available on the ENTSO-E transparency platform (ENTSO-E, 2018b), complemented with own calculations. The installed capacity of onshore wind, offshore wind and solar photovoltaics is updated based on WindEurope (2018a,b) and SolarEurope (2018). Must-run technologies (waste, geothermal, hydro, peat, other, marine, biomass - 215,994 MW in total according to ENTSO-E (2018b)) are treated as a demand correction. All capacity is aggregated per technology (Table 4). Decommissioning rates, which are assumed to be linear, for currently installed capacity are based on the lifetime of the technology and the estimated average age of the current installed capacity. The lifetime, operating cost and carbon intensity of each technology is based on data from the Ten Year Network Development Plan (ENTSOE, 2018a). The average age of the current installed capacity is based on assumptions of the authors, as commissioning dates are typically not available. Investment costs of thermal generation capacity were taken from International Energy Agency (IEA) (2015). Investment costs for thermal technologies are assumed to remain constant in the period 2017-2061. Onshore wind power, offshore wind power and solar power investment costs are taken from International Energy Agency (IEA) (2015) and assumed to decrease annually by 2\%. The operating costs of conventional technologies are based on the efficiency of the technology, taken from ENTSO-E (2018a), and historic fuel prices and fuel price projections (BP, 2017; ENTSO-E, 2018a). Unless stated otherwise, the nuclear, coal-fired and lignite-fired capacity may not exceed the aggregated capacity of each technology in 2017. In other words, only phased-out capacity may be replaced by new investments. The nominal discount rate is set to $10 \%$.

Time series for the load, generation from renewable energy sources and must-run technologies for calendar year 2017 are obtained from ENTSO-E (2018b). The net load profile, i.e., the load corrected for must-run generation, and profiles characterizing the availability of onshore wind, offshore wind and solar power are reduced to four representative days, optimally selected throughout the calendar year via the method introduced by Poncelet et al. (2017). The demand growth is based on the EU Reference Scenario 2016 (Fig. 15 in European Commission (2016)): $+0.1 \%$ in $2010-2020,+0.45 \%$ in $2020-2030$ and $+0.71 \%$ in 2030-2061. This growth rate reflects the aggregate effect of electrification, adoption of new technologies and energy efficiency measures across all sectors.

The 2020 RES target (34\% of the electricity demand in 2020) is enforced as of 2020, since it is more stringent than the 2030 target (32\% of the electricity demand in 2020) considering the demand growth rates above (Section 3.1.3). The contribution of renewable must-run technologies, such as hydro and biomass, is estimated at 16.5\% in 2018 and subtracted from the RES target in absolute terms. ${ }^{14}$ The output of RES-based and other must-run technolo-

\footnotetext{
${ }^{14}$ According to the latest EUROSTAT data, retrieved from https://ec.europa.eu/eurostat/web/ energy/data/shares.
} 
Table 3. Average operating costs, efficiency and carbon intensity, based on the Ten Year Network Development Plan by ENTSO-E (2018a) and 2017 fuel prices as reported by BP (2017). Operating costs for all other years are obtained by linear interpolation. Other costs, such as ramping costs, variable operating \& maintenance costs and start-up or shut-down costs, are not considered. Operating costs are expressed in nominal terms.

\begin{tabular}{lcccc}
\hline \hline & $\begin{array}{c}\text { Operating } \\
\text { efficiency } \\
(-)\end{array}$ & $\begin{array}{c}\text { Carbon } \\
\text { intensity } \\
\left(\mathrm{tCO}_{2} / \mathrm{MWh}\right)\end{array}$ & $\begin{array}{c}\text { Operating } \\
\text { cost }(2017) \\
(€ / \mathrm{MWh})\end{array}$ & $\begin{array}{c}\text { Operating } \\
\text { cost }(2030) \\
(€ / \mathrm{MWh})\end{array}$ \\
\hline Nuclear & 0.33 & 0 & 5.0 & 5.0 \\
SPP - Lignite (old) & 0.30 & 1.11 & 13.2 & 13.2 \\
SPP - Lignite (new) & 0.40 & 0.83 & 9.9 & 9.9 \\
SPP - Coal (old) & 0.30 & 1.18 & 15.9 & 34.9 \\
SPP - Coal (new) & 0.40 & 0.89 & 12.0 & 26.1 \\
SPP - Natural gas & 0.30 & 0.60 & 70.1 & 100.3 \\
CCGT - Natural gas (old) & 0.40 & 0.45 & 52.6 & 75.2 \\
CCGT - Natural gas (new) & 0.58 & 0.31 & 36.3 & 51.9 \\
OCGT - Natural gas & 0.35 & 0.52 & 60.1 & 86.0 \\
ICE - Oil & 0.30 & 0.83 & 85.8 & 141.5 \\
\hline \hline
\end{tabular}

gies is assumed persistent over the period 2017-2061, i.e., replaced by similar technologies if they reach the end of their lifetime.

Focusing on the electric power sector and its interaction with the EU ETS, industrial emissions are based on the relation between EUA prices and $\mathrm{CO}_{2}$ emissions provided by Landis (2015). In our analysis, we calculate the emissions for the energy-intensive industry via the quartic polynomial fit of the relation between EUA prices and the exponential abatement as obtained from PACE, a computable general equilibrium model. ${ }^{15,16}$ The resulting emissions are rescaled according to the current share of the energy-intensive industry in the emissions covered by the ETS (43.5\% accoriding to Agora Energiewende (2016)) and limited to the current emission level (737 $\mathrm{MtCO}_{2}$ (Sandbag, 2017b)). Since these curves are only available for 2020, 2025, 2030, 2035, 2040, 2045 and 2050, intermediate values are obtained via linear interpolation. Post-2050, we extrapolate Landis' results using the evolution of $\mathrm{CO}_{2}$ emissions between 2045 and 2050.

\footnotetext{
${ }^{15}$ Landis $(2015)$ expresses the EUA price in $€ 2010$. In this paper, we employ a constant inflation rate of $2 \% /$ year to link these results to the nominal EUA price.

${ }^{16}$ Schopp et al. (2015) employ a quadratic abatement cost curve to represent abatement costs, obtained by least-square fits w.r.t. the results of Landis (2015). Similarly, Perino and Willner (2017) employ a time-invariant quadratic abatement cost curve. In this paper, however, we propose to employ the quartic polynomial fit of the exponential of abatement, which captures the relation between emissions and EUA prices more accurately, especially at high abatement values (Landis, 2015). As discussed in Section 1, the reinforcing effect that exists between increasing abatement costs related to meeting the future emissions cap and the cancellation volume requires accurately describing marginal abatement costs in quantitative assessments of the impact of the MSR. This representation of the relation between emissions and EUA prices via a high-degree polynomial is enabled by our solution concept based on ADMM.
} 


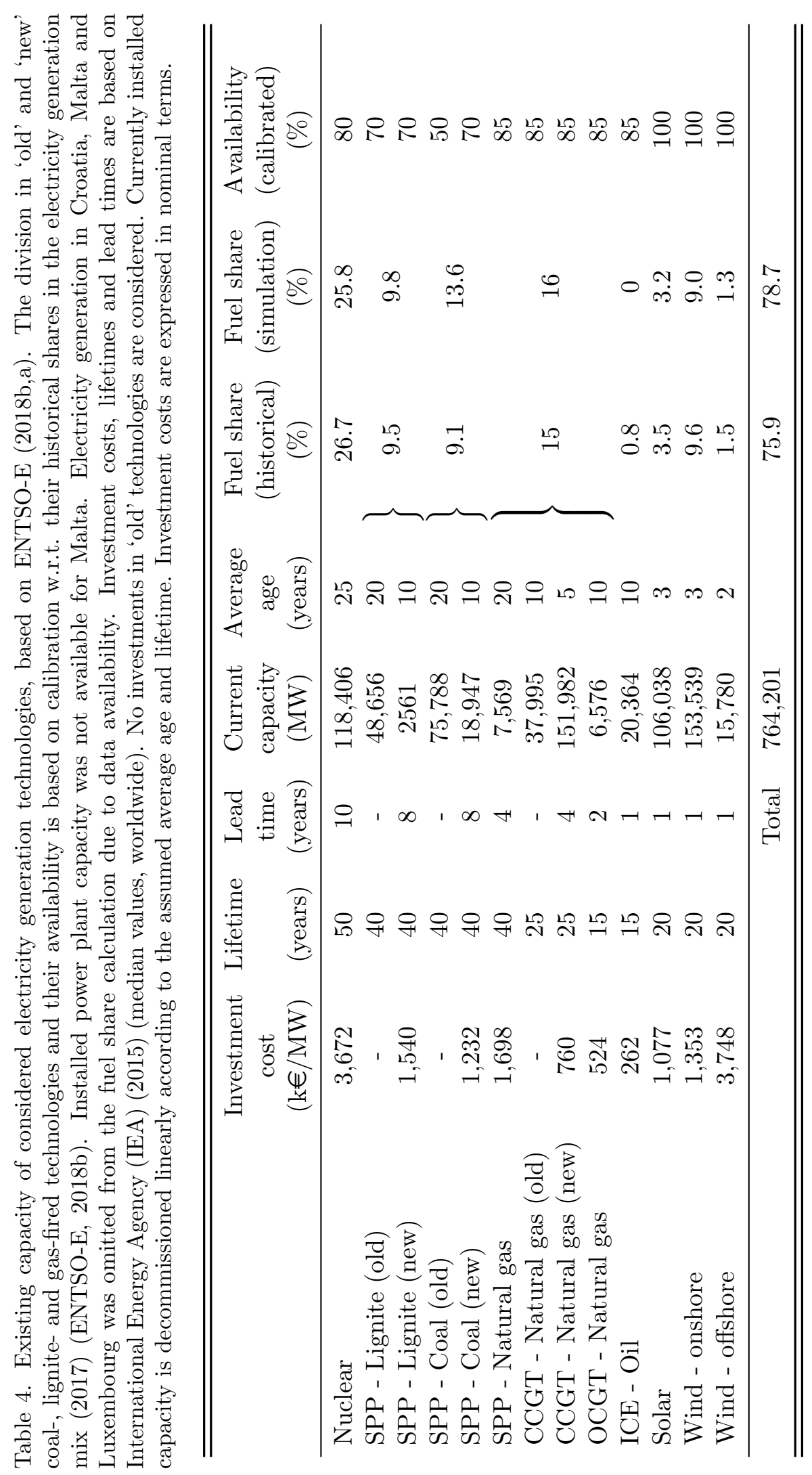


Note that for the starting year of our analysis (i.e., 2017), investments are not allowed. The electricity demand in 2017-2018 must thus be met by already installed capacity, hence, the availability of the current installed thermal capacity may be calibrated by comparing the fuel shares resulting from the model in the reference case and those reported by ENTSO-E and Sandbag for the year 2017 (ENTSO-E, 2018b; Sandbag, 2017b) and iteratively updating the availability factors of legacy capacity. The resulting availability and fuel share of each technology is reported in Table 4. Furthermore, we consider an EUA price of $5 € / \mathrm{tCO}$ in 2017-2018, reflecting the assumption that emitters procured EUAs prior to the price hike in the second half of 2018 (Fig. 1). After calibration of the availability of legacy capacity, the simulated $\mathrm{CO}_{2}$ emissions of the power sector in 2017 amount to $986 \mathrm{MtCO}_{2}$ in our reference case, close to historical $\mathrm{CO}_{2}$ emissions of $1,013 \mathrm{MtCO}_{2}$ (Sandbag, 2017a). The $\mathrm{CO}_{2}$ emissions of the energy-intensive industry in 2017 are fixed to $737 \mathrm{MtCO}_{2}$ (Sandbag, 2017a).

\section{Results \& Discussion}

First, we discuss the impact of the strengthened EU ETS on the power sector in the reference scenario (Section 5.1). In Section 5.2, we study how this impact depends on parameter assumptions in a number of policy scenarios. Last, Section 5.3 analyzes the total cost associated with these policies.

\subsection{The impact of the strengthened EU ETS under reference assumptions}

We focus our attention on (i) the change in EUA prices, EUA supply \& surplus, MSR holdings and cancellation volumes; (ii) $\mathrm{CO}_{2}$ emissions and (iii) the evolutions in the power sector, as well as the associated average wholesale electricity price and the REC price (Fig. 2). To underpin the evolutions in the ETS, we also show the developments in electricity generation capacity, including the deployment of renewable technologies. As a benchmark, we compare our reference policy scenario of the strengthened ETS ('MSR2018') with the policies in place before 2018 ('MSR2015'): the LRF is set to $1.74 \%^{17}$, no additional RES target is enforced for 2030, the intake and outflow rate of the MSR prior to 2024 is not doubled and no cancellation is enforced.

\subsubsection{Evolution of the EUA price, EUA supply, MSR holdings $\&$ cancellation volume}

As we will discuss at length below, the cancellation provision of the strengthened MSR leads to a EUA price increase $(+303 \%)$ and a decrease in cumulative emissions $\left(13.9 \mathrm{GtCO}_{2}\right)$

\footnotetext{
${ }^{17} \mathrm{An}$ increase in the LRF has been under discussion since 2015 and is in line with the European Commission's pledge at COP21 in 2015, but was only enforced by law by the European Union in 2018 (European Union, 2018). Motivated by the lack of response of the market in 2015 (Fig. 1), we opt to keep the LRF at $1.74 \%$ in the 'MSR2015' scenario. However, one could argue that the market should have anticipated this policy change and, hence, our counter-factual reference scenario 'MSR2015' is not sufficiently ambitious, inflating the importance of the 2018 legislative package. Therefore, we investigate the impact of each of the changes to the ETS (increased LRF, doubled intake rates of the MSR and cancellation) and the RES targets individually in Section 5.2.
} 
that significantly exceeds the emission reductions triggered by the increased LRF (8.3 $\mathrm{GtCO}_{2}$ ). At the root of these emission reductions lies the self-reinforcing effect that exists between the marginal cost of abatement associated with the future emissions cap and the cancellation volume (Bruninx et al., 2019). With the increase of the LRF, the marginal cost of meeting the emissions cap increases, which in turn makes banking allowances for future use more profitable. However, this in turn increases the surplus today and in the near future, hence, the volume of allowances absorbed and cancelled by the MSR. This feedback effect translates the cancellation provision, active over multiple decades, into a strong signal for decarbonization today.

As such, the revised MSR and the increase of the LRF ('MSR2018') results in a 303\% increase in the price of EUAs, from $6.8 € / \mathrm{tCO}_{2}$ to $27.4 € / \mathrm{tCO}_{2}$ in 2019 (Fig. 2a). As the EUA price profile is inversely proportional to the discount factor if the aggregate surplus is non-zero (Perino and Willner, 2017), i.e., $\lambda_{y}^{\text {ETS }} \sim \frac{1}{(1+r)^{y}}, \quad \forall y \in \mathcal{Y}$, the price of EUAs will continue to be $303 \%$ higher up to 2049, when the surplus reaches zero in the 'MSR2015' scenario. After 2049, the price in the 'MSR2018' scenario increases with the discount factor, while the price in the 'MSR2015' scenario is such that supply of EUAs equals its demand.

The combination of the cancellation policy and the increased LRF results in a lower net supply of EUAs over the whole horizon compared to the '2015' scenario (Fig. 2c). The increased LRF lowers the annual cap (Fig. 2c, 'C'), while the MSR and cancellation further lower the net supply (Fig. 2c, 'S'). In the first years of operation of the MSR, the doubled intake rates and the high TNAC lead to an aggressive decrease in the net supply (Fig. 2c).

In the 'MSR2018' scenario, we observe that $\mathrm{CO}_{2}$ emissions and net supply approximately coincide between 2020 and 2023, such that the TNAC remains relatively stable between 1,734 and 1,911 $\mathrm{MtCO}_{2}$ (Fig. 2d). After 2023, the combination of the lower MSR intake rate and the elevated EUA price, triggered by the above-mentioned self-reinforcing effect, causes $\mathrm{CO}_{2}$ emissions to fall below the net supply, resulting in increasing TNAC levels (Fig. $2 \mathrm{~d}$ ). The MSR peaks at 3,348 $\mathrm{MtCO}_{2}$ in 2022, just before the start of the cancellation. After attaining its maximum in $2035\left(3,067 \mathrm{MtCO}_{2}\right)$, the $\mathrm{TNAC}$ decreases when $\mathrm{CO}_{2}$ emissions start to exceed the net supply. Note that, contrary to the objective of the strengthened MSR, the TNAC remains above the $833 \mathrm{MtCO}_{2}$ threshold for several decades, which causes the MSR to absorb and cancel EUAs from 2019 till 2059, when the emissions cap becomes zero (Fig. 2d). In contrast, the TNAC level in the 'MSR2015' scenario rapidly decreases from 2019 onwards (Fig. 2d), because the lower EUA price keeps $\mathrm{CO}_{2}$ emissions above net supply in 2020-2029 (Fig. 2c) and the MSR absorbs EUAs until 2029 and in 2036-2040. Because there is no cancellation, the MSR continues to increase and peaks in 2041-2045, when it contains 4,172 $\mathrm{MtCO}_{2}$. In 2029-2034 and 2040-2045, the net supply of EUAs equals the cap, whereas after 2045 the MSR releases allowances, increasing the annually available net annual supply to 100 million above the $\mathrm{CO}_{2}$ emissions cap. Due to a brief period in which $\mathrm{CO}_{2}$-emissions remain below the emissions cap after 2030, the TNAC temporarily increases between 2030 and 2035, but drops again to values below the $833 \mathrm{MtCO}_{2}$ threshold by 2040. At the end of our horizion (2061), the MSR still contains 2,639 $\mathrm{MtCO}_{2}$, which under the 'MSR2015' policies are to be released over the period 2061-2089. 
In total, $13,009 \mathrm{MtCO}_{2}$ or $29.7 \%$ of the cumulative cap (assuming the $2.2 \%$ LRF post2020 ) is taken out of the system via the cancellation policy. ${ }^{18}$ The highest cancellation volume is recorded in 2023, when $2,783 \mathrm{MtCO}_{2}$ is taken out of the system. ${ }^{19}$ Note that the cancellation volume in 2023 exceeds the volume of back-loaded and unallocated EUAs $\left(1,600 \mathrm{MtCO}_{2}\right.$, Table 2) placed in the MSR.

\subsection{2. $\mathrm{CO}_{2}$ emissions from the energy-intensive industry 80 power sector}

Cumulative $\mathrm{CO}_{2}$ emissions equal 30,812 $\mathrm{MtCO}_{2}$ in the 'MSR2018' scenario and are $41 \%$ or 21,334 $\mathrm{MtCO}_{2}$ below the cumulative cap before the strengthening of the ETS $(52,150$ $\left.\mathrm{MtCO}_{2}\right){ }^{20}$ Around $40 \%$ of this decrease $\left(8,332 \mathrm{MtCO}_{2}\right)$ is due to the increased linear reduction factor, which lowers the cumulative cap from 52,150 $\mathrm{MtCO}_{2}$ to $43,819 \mathrm{MtCO}_{2}$. The remaining $60 \%$ of this decrease is the result of the cancellation policy $\left(13,009 \mathrm{MtCO}_{2}\right)$.

Power sector-related $\mathrm{CO}_{2}$ emissions decrease from $19,115 \mathrm{MtCO}_{2}$ to $11,820 \mathrm{MtCO}_{2}$ (Fig. 2e). The $\mathrm{CO}_{2}$ emissions of the energy-intensive industry equal 18,993 $\mathrm{MtCO}_{2}$ ('MSR2018') and 30,393 $\mathrm{MtCO}_{2}$ ('MSR2015'). The energy-intensive industry is not yet fully decarbonized by 2061, despite the strengthened ETS (Fig. 2e). In the 'MSR2015' case, we only observe significant decarbonization in the energy-intensive industry post 2050 (Fig. 2e). These, in some cases abrupt, changes in $\mathrm{CO}_{2}$ emissions are, of course, a direct result of our representation of (i) the energy-intensive industry and their abatement options and (ii) the investment options in the power sector. For example, by 2020, we observe a $18.9 \%$ decrease in $\mathrm{CO}_{2}$ emissions (3.9\% in the 'MSR2015' case) compared to 2017-levels. However, two-thirds of this drop in $\mathrm{CO}_{2}$ emissions stems from fuel switching in the power sector (i.e., replacing lignite- and coal-fired generation with natural gas-fired generation using existing capacity), which is realistically represented in the model (Section 5.1.3).

\subsubsection{Evolutions in the power sector, electricity and REC prices}

The $\mathrm{CO}_{2}$ emissions in the power sector (Fig. 2e) are directly linked to changes of the electricity generation fuel mix (Fig. 2f). Despite the large difference in EUA prices and supply between the 'MSR2015' and the 'MSR2018' case, the trends in the power sector are very similar (Fig. 2f). However, as the EUA price required for certain technology

\footnotetext{
${ }^{18}$ We calculate total cancellation volume as the cumulative difference between the cap and $\mathrm{CO}_{2}$ emissions. The cumulative cap equals $43,819 \mathrm{MtCO}_{2}$ and is calculated as the sum of the annual cap as of 2018, the effective supply in $2017\left(1,764 \mathrm{MtCO}_{2}\right)$, the surplus at the end of $2017\left(1,693 \mathrm{MtCO}_{2}\right)$, back-loaded allowances $\left(900 \mathrm{MtCO}_{2}\right)$ and unallocated allowances in Phase $3\left(700 \mathrm{MtCO}_{2}\right)$ (Sandbag, 2017a).

${ }^{19}$ As a comparison, Perino and Willner (2017) calculate that $1700 \mathrm{MtCO}_{2}$ is canceled in 2023, while Carlén et al. (2018) find $2400 \mathrm{MtCO}_{2}$. Sandbag (2017a) reports a cancellation volume in 2023 between 2,791 and $3,123 \mathrm{MtCO}_{2}$, depending on their assumptions w.r.t. $\mathrm{CO}_{2}$ emission trajectories.

${ }^{20}$ The cumulative $\mathrm{CO}_{2}$ emissions in the 'MSR2018' policy scenario are $37.8 \%$ or $18,695 \mathrm{MtCO}_{2}$ below those observed in the 'MSR2015' scenario over the period 2017-2061. In the 'MSR2015' scenario, the MSR is, however, not fully depleted by the end of 2061 in absence of a cancellation policy. Consequently, cumulative $\mathrm{CO}_{2}$ emissions (49,507 $\mathrm{MtCO}_{2}$ ) are 2,639 $\mathrm{MtCO}_{2}$ (the holdings of the MSR at the end of 2061) lower than the cumulative cap $\left(52,150 \mathrm{MtCO}_{2}\right)$ (Fig. 2c-2e). As these allowances are to be released after $2061, \mathrm{CO}_{2}$ emissions will be equal to the cumulative cap. Therefore, we will compare $\mathrm{CO}_{2}$ emissions to the cumulative cap before the strengthening of the ETS.
} 
shifts is reached earlier, these transitions occur sooner in the 'MSR2018' scenario. Before 2030, we observe fuel switching (Delarue and D'haeseleer, 2008) from coal- and lignite-fired generation to gas-fired generation (Fig. 2f). After 2030, onshore wind power becomes the dominant electricity generation technology due to increasing EUA prices and falling wind power investment costs. Prior to 2027, wind and solar power deployment is similar in both scenarios because of the binding RES target \& support under the form of REC. At the same time, nuclear capacity is gradually phased out, but is partially replaced by new nuclear units after 2035 (Fig. 2f). This last effect is less pronounced in the 'MSR2015' scenario. Nuclear units generate, on average, $435 \mathrm{TWh} / \mathrm{a}$ in the period 2040-2061 in the 'MSR2018' scenario, compared to $72 \mathrm{TWh} / \mathrm{a}$ under the 'MSR2015' policy.

The increased EUA price is transferred to electricity consumers through elevated EOM prices, as illustrated by the average annual electricity prices $\lambda_{y}^{\mathrm{EOM}}$ (Fig. 2b). Compared to the electricity prices in the 'MSR2015' scenario, differences in average prices range from $-6.9 € / \mathrm{MWh}$ to $+19.6 € / \mathrm{MWh}$. Across the model horizon, the average electricity price is $5.2 € /$ MWh higher in the 'MSR2018' case. However, in the period 2020-2040, these differences are more pronounced, with electricity prices that are on average $10.3 € / \mathrm{MWh}$ higher. After 2040, the difference reduces, on average, to $+0.5 € / \mathrm{MWh}$. Indeed, because the power sector is almost completely decarbonized by 2040 in the 'MSR2018' scenario, the EUA price becomes a minor component in the EOM price.

The MSR and LRF also affect the price of RECs required to reach the RES targets. Compared to the 'MSR2015' case, the price of a REC is, on average over the period 20202030, 7.9 $€ /$ MWh lower under the strengthened ETS, lowering the overall out-of-market payments required to meet the targets from $45.3 \mathrm{~B} €$ ('MSR2015') to $20.4 \mathrm{~B} €$ ('MSR2018'). Note furthermore that, due to the combination of EUA prices, RES targets and falling investment costs of renewable technologies, the resulting RES share in 2030, expressed as a percentage of the load in that year, equals $57.8 \%$ in the 'MSR2018' scenario, whereas it equals $32.6 \%$ in the 'MSR2015' case.

However, to properly interpret these changes in, i.a., electricity, EUA and REC prices, one has to compare the overall change in total cost induced by the strengthened ETS, an issue which we will return to in Section 5.3. 


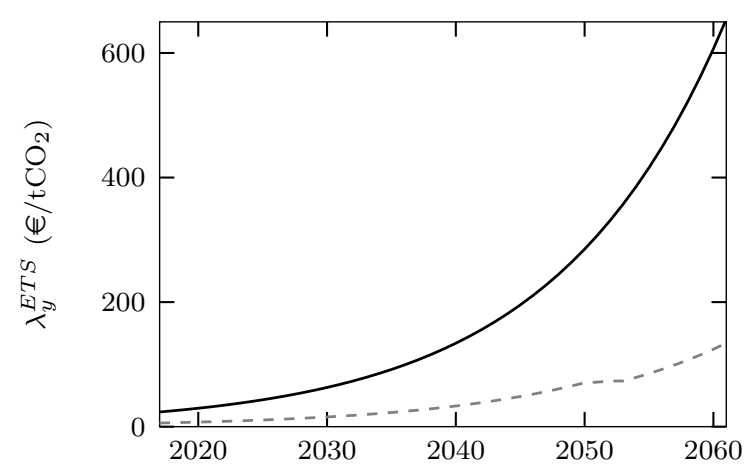

(a) EUA price $\lambda_{y}^{\text {ETS }}$.

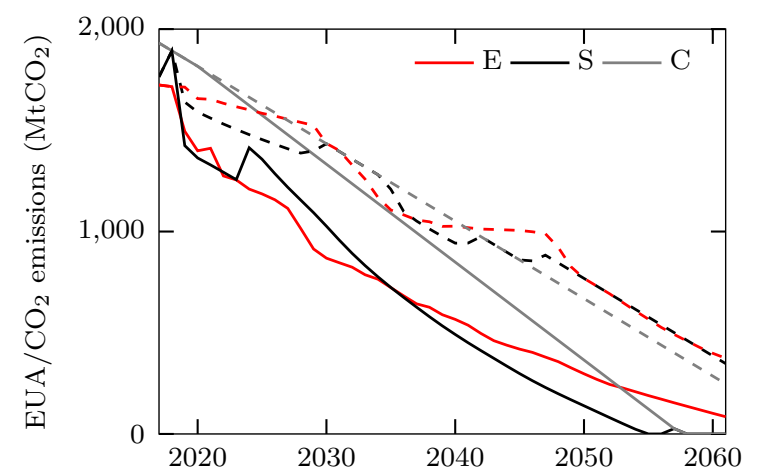

(c) $\mathrm{CO}_{2}$ emissions (E), net supply (S) of EUAs and the annual cap $(\mathrm{C})$.

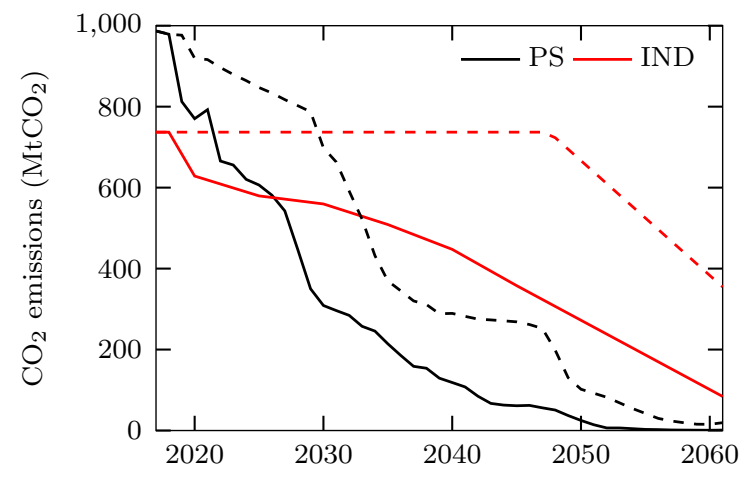

(e) $\mathrm{CO}_{2}$ emissions of the power sector (PS) and energy-intensive industry (IND).

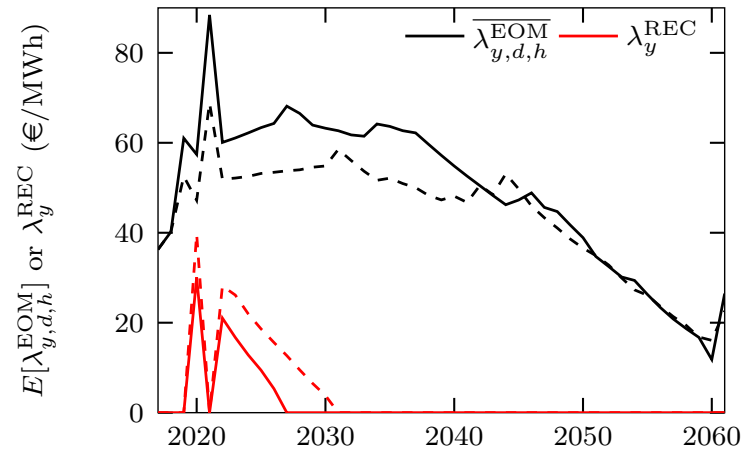

(b) REC price $\lambda^{\mathrm{REC}}$ and annual average electricity price $\overline{\lambda_{y, d, h}^{\mathrm{EOM}}}$.

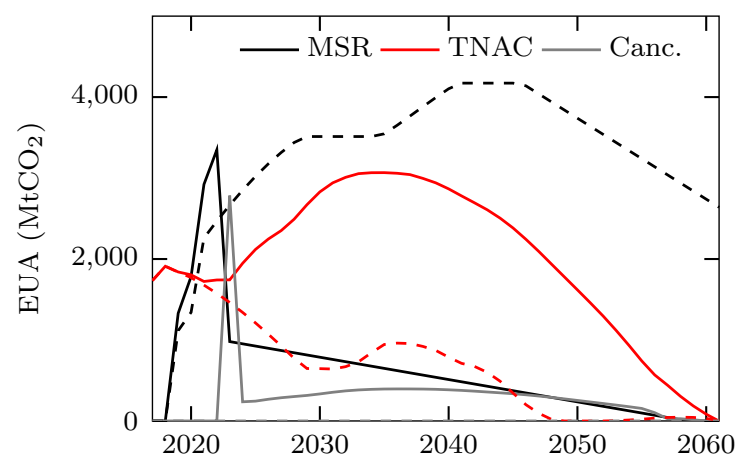

(d) Holdings of the MSR, TNAC and cancellation (Canc.).

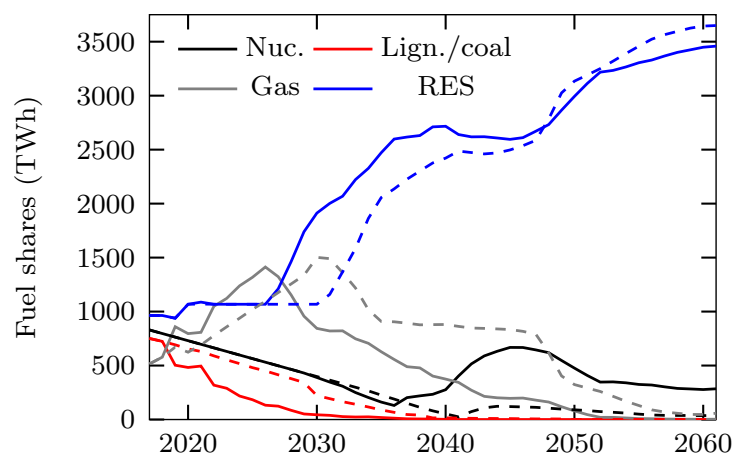

(f) Share of nuclear energy (Nuc.), natural gas (Gas), renewables (RES) and lignite and coal (Lign./coal) in the power sector.

Figure 2. The price of ETS emission allowances (Fig. 2a), the average annual electricity price and REC price per year (Fig. 2b) and the net supply of allowances, accounting for the impact of the MSR (Fig. 2c) in the 'MSR2018' and 'MSR2015' scenarios. Figures 2d-2f show the TNAC, holdings of the MSR and the amount of cancelled allowances (Fig. 2d), the $\mathrm{CO}_{2}$ emissions of the power sector and energy-intensive industry (Fig.2e) and the fuel shares in the power sector (Fig. 2f). The dashed lines are the results of the 'MSR2015'-case, whereas the solid lines correspond to the 'MSR2018'-case. All prices are expressed in real terms (€2017), assuming inflation at $2 \% /$ year. 
Table 5. The considered policy scenarios, which differ w.r.t. the assumed linear reduction factor (LRF) after 2021, the intake and outflow rates of the MSR in the period 2019-2023, the consideration of the cancellation provision and the RES target imposed on the power sector in the two reference years (2020 and 2030). Recall that in all policy scenarios the 2020 renewable energy target of $34 \%$ in the power sector remains binding after 2020. As of 2030, the 2020 or 2030 renewable energy target is assumed to be binding, depending on which is more stringent.

\begin{tabular}{lcccc}
\hline \hline Policy scenario & LRF & MSR 2019-2023 & Cancellation & Power sector RES target \\
\hline MSR2018 & $2.2 \%$ & $24 \%-200 \mathrm{MtCO}_{2}$ & $\checkmark$ & $34 \%(2020)-32 \%(2030)$ \\
MSR2015 & $1.74 \%$ & $12 \%-100 \mathrm{MtCO}_{2}$ & $\boldsymbol{x}$ & $34 \%(2020)$ \\
MSR2018-LRF1.74 & $1.74 \%$ & $24 \%-200 \mathrm{MtCO}_{2}$ & $\checkmark$ & $34 \%(2020)-32 \%(2030)$ \\
MSR2018-RES50 & $2.2 \%$ & $24 \%-200 \mathrm{MtCO}_{2}$ & $\checkmark$ & $34 \%(2020)-50 \%(2030)$ \\
MSR2018-NC & $2.2 \%$ & $24 \%-200 \mathrm{MtCO}_{2}$ & $\boldsymbol{x}$ & $34 \%(2020)-32 \%(2030)$ \\
\hline \hline
\end{tabular}

\subsection{Policy scenario $\&$ sensitivity analysis}

In our analysis above, one is not able to identify how much each of the changes in policy (i.e., the increased LRF, the higher intake and outflow rates of the MSR, the introduction of cancellation or the 2030 RES target) contribute to the changes discussed above. Therefore, to isolate the impact of the major changes to the ETS and 2030 renewable energy targets that have been adopted in 2018, we consider five policy scenarios, summarized in Table 5 . 'MSR2018' is our central reference scenario, in which the strengthened MSR is deployed, the LRF is increased to $2.2 \%$ as of 2021 , a power sector renewable energy target of $32 \%$ by 2030 is enforced and the cancellation provision of the MSR is enabled. This scenario is designed to reflect the current policies. In our counter-factual scenario 'MSR2015', the renewable energy target in the power sector is $34 \%$ by 2020 , the LRF remains at $1.74 \%$, the intake and outflow rates of the MSR are always equal to $12 \%$ of the TNAC and $100 \mathrm{MtCO}_{2}$ and cancellation of EUAs is not considered. This scenario is in line with the policies instated in 2015. The remaining policy scenarios are variations on the 'MSR2018' scenario, in which one of the policy parameters is adapted: the LRF is set to $1.74 \%$ in scenario 'MSR2018LRF1.74'; a more stringent power sector RES target of $50 \%$ by 2030 is enforced in scenario 'MSR2018-RES50' and 'MSR2018-NC' case does not consider the cancellation provision.

In addition, we stress-test the robustness of our results in each of these policy scenarios w.r.t. key assumptions on investment and operating costs in the power sector, the options to invest in new nuclear or lignite and coal-fired power plants, demand growth, abatement costs in industry and discount rates, as summarized in Table 6. For each of our policy scenarios, we consider 16 alternative cases, in addition to our reference assumptions on the parameters listed in middle column in Table 6 . In each of those cases, we vary one of these parameters ceteris paribus to the values indicated in Table 6. For example, an increased demand growth rate may reflect increased abatement-driven electrification in the energy-intensive industry or other sectors - an effect we do not explicitly model due to the inherent uncertainty on the link between abatement and electrification, see Section 3.1.3 and McKinsey \& Company (2018) -, less successful energy efficiency measures or an increased uptake of certain technologies, such as power-to-X, heat pumps or electric vehicles. 
Table 6. Assumptions on critical parameters in our sensitivity analysis. The central values are our reference assumptions. For each policy scenario, we consider 16 alternative sets of parameters, in which we vary the assumption on one of the parameters listed below, ceteris paribus.

\begin{tabular}{lccc}
\hline \hline & \multicolumn{2}{c}{ Considered parameter values } \\
\hline Reduction investment cost on- \& offshore wind power & $-1 \% /$ year & $-2 \% /$ year & $-3 \% /$ year \\
Reduction investment cost solar power & $-1 \% /$ year & $-2 \% /$ year & $-3 \% /$ year \\
Limit on investment in nuclear power plants & 0 & $\overline{C P_{2017}}-\overline{C P_{y}}$ & $\infty$ \\
Limit on investment in lignite- \& coal-fired power plants & 0 & $\overline{C P_{2017}}-\overline{C P_{y}}$ & $\infty$ \\
Natural gas price (w.r.t reference scenario) & $-50 \%$ & $+/-0 \%$ & $+50 \%$ \\
Demand growth rate (w.r.t reference scenario) & $-50 \%$ & $+/-0 \%$ & $+100 \%$ \\
Abatement cost in industry (w.r.t reference scenario) ${ }^{21}$ & $-20 \%$ & $+/-0 \%$ & $+20 \%$ \\
Nominal discount rate & $8 \%$ & $10 \%$ & $12 \%$ \\
\hline \hline
\end{tabular}

In addition, these results allow exposing the strength of the self-reinforcing feedback effect between the future marginal abatement costs and the cancellation volume (Bruninx et al., 2019) within each policy scenario considering a MSR with a cancellation provision. For example, elevated natural gas prices will increase the cost of switching from lignite and coal-based generation to natural gas-fired generation in the power sector. This provides an incentive to bank allowances in the near future, elevating the surplus, hence, the number of allowances absorbed and cancelled by the MSR.

In what follows, we first dive into the performance of the ETS in these policy scenarios (Section 5.2.1). Subsequently, the changes in the power sector are discussed in Section 5.2.2. Last, the implications on total costs are discussed (Section 5.3).

\subsubsection{Bird's eye overview of changes in the ETS}

Figure 3 summarizes the results per policy scenario, as indicated by the different colors, considering seventeen different sets of input parameters (see above). As Fig. 3 illustrates, the introduction of the 2018-legislative package triggers signficant ETS price increases and $\mathrm{CO}_{2}$ emissions reductions w.r.t. those observed under the 'MSR2015' scenario. However, several additional observations may be made.

First, increasing the LRF from $1.74 \%$ to $2.2 \%$ as of 2021 reduces the cumulative cap by $8.3 \mathrm{GtCO}_{2}$ from $52.2 \mathrm{GtCO}_{2}$ to $43.9 \mathrm{GtCO}_{2}$, which leads to a strong reduction in $\mathrm{CO}_{2}$ emissions across all parameter sets (Fig. 3, E). On average, cumulative $\mathrm{CO}_{2}$ emissions over the period 2017-2061 amount to $49.2 \mathrm{GtCO}_{2}$ in the 'MSR2015' scenario and to $47.9 \mathrm{GtCO}_{2}$ in the 'MSR2018-LRF1.74'-case, which is to be compared with $31.0 \mathrm{GtCO}_{2}$ in our reference 'MSR2018'-case. ${ }^{22}$ In the policy scenario with cancellation but without the increased LRF ('MSR2018-LRF1.74'), cancellation volumes (4.1 $\mathrm{GtCO}_{2}$ under reference assumptions) remain modest compared to those observed in the reference policy scenario 'MSR2018'. At the

\footnotetext{
${ }^{21}$ In scenario '-20\%', the energy-intensive industry abates $20 \%$ less compared to the reference scenario in response to the same EUA price.

${ }^{22}$ Recall that under the 'MSR2015' scenario, the MSR is not depleted at the end of the model horizon, hence, cumulative $\mathrm{CO}_{2}$ emissions may increase to the cap $\left(52.2 \mathrm{GtCO}_{2}\right)$.
} 
root of this difference in cumulative emissions under policy scenarios 'MSR2018-LRF1.74' and 'MSR2018' lies the self-reinforcing feedback effect between the marginal abatement cost to meet the future cap and the cancellation volume (Bruninx et al., 2019). Indeed, increasing the LRF reduces the supply of allowances, hence, increases the cost of meeting the cap in the future. Consequently, this provides an incentive to bank allowances today, hence, increases the TNAC, the volume of allowances absorbed and cancelled by the MSR (Fig. 3, C). Moreover, EUA prices remain low (Fig. 3, $\lambda_{2020}^{\mathrm{ETS}}$ ) and equal to $7.33 € / \mathrm{tCO}_{2}$ ('MSR2015') and 8.40 $€ / \mathrm{tCO}_{2}$ ('MSR2018-LRF1.74'). This allows higher $\mathrm{CO}_{2}$ emissions (Fig. 3, E), especially from the energy-intensive industry (Fig. 3, E-IND): $29.6 \mathrm{GtCO}_{2}$ ('MSR2018-LRF1.74') to $30.4 \mathrm{GtCO}_{2}$ ('MSR2015'), compared to $19.0 \mathrm{GtCO}_{2}$ in the 'MSR2018' scenario. In the power sector, this effect is less pronounced and more dependent on cost evolutions, interactions with the RES targets and the availability of certain technologies. Average cumulative $\mathrm{CO}_{2}$ emissions from the power sector equal $18.5 \mathrm{GtCO}_{2}$ ('MSR2018-LRF1.74') to $18.9 \mathrm{GtCO}_{2}$ ('MSR2015'), compared to $12.0 \mathrm{GtCO}_{2}$ in the reference policy scenario (Fig. 3, E-PS).

Second, the introduction of a stringent RES target in 2030 has a modest impact on the cumulative $\mathrm{CO}_{2}$ emissions (Fig. 3, E). Averaged across the seventeen results per policy scenario, moving to a $50 \%$ RES target reduces the cumulative $\mathrm{CO}_{2}$ emissions from 31.0 $\mathrm{GtCO}_{2}$ to $30.2 \mathrm{GtCO}_{2}$. These $\mathrm{CO}_{2}$ emission reductions are entirely realized in the power sector and occur during a period of continued surplus in the ETS, hence trigger higher cancellation volumes (Fig. 3, C). On average, cancellation volumes increase from $12.8 \mathrm{GtCO}_{2}$ ('MSR2018') to 13.6 GtCO $_{2}$ ('MSR2018-RES50'). Consequently, the expected EUA pricedepressing effect of RES targets is dampened, as the additional excess EUAs are cancelled. In fact, average EAU prices in 2020 are slightly higher in the 'MSR2018-RES50' scenario: $30.2 € /$ ton $\mathrm{CO}_{2}$ compared to $30 € /$ ton $\mathrm{CO}_{2}$ in the reference policy scenario 'MSR2018'. This marginally decreases $\mathrm{CO}_{2}$ emissions from the energy-intensive industry from $19.0 \mathrm{GtCO}_{2}$ to $18.9 \mathrm{GtCO}_{2}$ under reference assumptions.

Third, the cancellation provision of the strengthened MSR leads to additional $\mathrm{CO}_{2}$ emission reductions (Figure 3, E). Cancellation volumes range from $5.7 \mathrm{GtCO}_{2}$ to $17.8 \mathrm{GtCO}_{2}$, with an average of $12.8 \mathrm{GtCO}_{2}$, in the 'MSR2018' scenario (Figure 3, C). Note that a strong interaction exists between the LRF and the cancellation provision due to the self-reinforcing feedback effect between the marginal abatement cost associated with meeting the future cap and the cancellation volume (see also first paragraph of this section). Higher linear reduction factors lead to (1) lower auction volumes and (2) higher EUA prices, hence higher TNAC volumes and absorption rates, which both may trigger higher cancellation volumes. Compare, e.g., cancellation volumes under 'MSR2018' policy assumptions and those observed in the 'MSR2018-LRF1.74' scenario (Fig. 3, C). As discussed above, a similar interaction exists between RES targets and the cancellation provision. However, this effect appeared to be less pronounced, as evidenced by the limited difference in cancellation volumes. In the policy scenarios without a cancellation provision, the difference between the cumulative cap and the cumulative emissions is stored in the MSR. This may depress emissions w.r.t. the cumulative cap in the period 2017-2061, but these allowances are, in principle, to be released post 2061. The holdings of the MSR at the end of 2061 equal on average $9.2 \mathrm{GtCO}_{2}$ ('MSR2018-NC') and $3.0 \mathrm{GtCO}_{2}$ ('MSR2015'). 


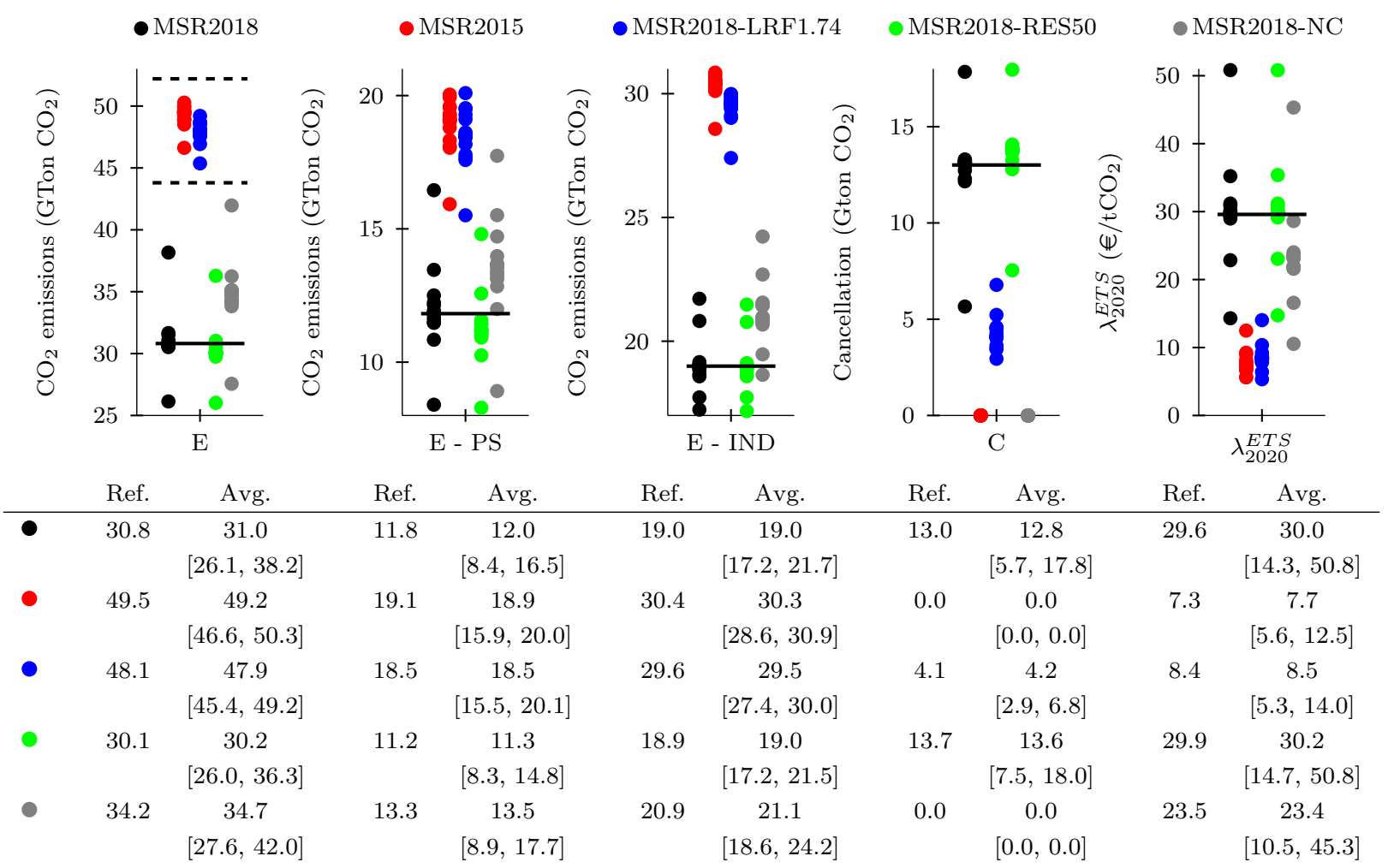

Figure 3. Cumulative $\mathrm{CO}_{2}$ emissions (E) over the period 2017-2061, split over the energy-intensive industry (E-IND) and power sector (E-PS), cumulative cancellation (C) and expected EUA prices in $2020 \lambda_{2020}^{E T S}$, grouped per policy scenario, as indicated by the different colors. The solid black line indicates the value in the reference scenario. The dashed lines in Fig. 3 (E) indicate the cumulative caps assuming a LRF of $1.74 \%$ or $2.2 \%$. Recall that in policy scenarios without a cancellation provision ('MSR2015' and 'MSR2018-NC'), effective cumulative $\mathrm{CO}_{2}$ emissions may increase to this cap post 2061. The table below summarizes the results for the five selected indicators under reference assumptions ('Ref.'), averaged across the seventeen results per policy scenario ('Avg.'), the minimum and maximum value (intervals).

Figure 3 also reveals significant differences in the results within each policy scenario, which all may be explained via their effect on today's perception of the marginal abatement cost today and in the future via the aforementioned feedback effect (Bruninx et al., 2019). For example, in the 'MSR2018' scenario, the cumulative $\mathrm{CO}_{2}$ emissions range from $26.1 \mathrm{GtCO}_{2}$ to $38.2 \mathrm{GtCO}_{2}$. These 'extreme' scenarios are triggered by different discount rates: a lower discount rate (8\%/year) triggers higher EUA prices today, as future marginal abatement costs are valued higher today, (Fig. 3, $\lambda^{E T S}$ ), which advances coal-natural gas switching (Section 5.2.2), depressing $\mathrm{CO}_{2}$ emissions in the power sector (Fig. 3, E-PS). Conversely, high discount rates (here: $12 \%$ /year) depress prices today, which delays coal-natural gas switching and, consequently, results in higher $\mathrm{CO}_{2}$ emissions in the power sector: 16.5 $\mathrm{GtCO}_{2}$, compared to $8.4 \mathrm{GtCO}_{2}$ (discount rate of $8 \% /$ year) or $11.8 \mathrm{GtCO}_{2}$ (discount rate of $10 \%$ ) (Fig. 3, E-PS). Advancing the switch to natural gas furthermore leads to a larger surplus in allowances, consequently, higher cancellation volumes: $17.8 \mathrm{GtCO}_{2}$, compared to $13.0 \mathrm{GtCO}_{2}$ (reference case) or $5.7 \mathrm{GtCO}_{2}\left(12 \% /\right.$ year) (Fig. 3, C). Remarkably, $\mathrm{CO}_{2}$ emissions from the energy-intensive industry are relatively stable, regardless of the discount 
rate, and range from $17.2 \mathrm{GtCO}_{2}(8 \%$ year $)$ to $21.7 \mathrm{GtCO}_{2}(12 \% /$ year) (Fig. 3, E-IND). As expected, these variations triggered by the discount rate are less pronounced in policy scenarios characterized by lower EUA prices ('MSR2015' and 'MSR2018-LRF1.74'). Neglecting the variations caused by the discount rate leads to a more 'stable' picture per policy scenario: in the reference policy scenario, cumulative $\mathrm{CO}_{2}$ emissions range from $30.5 \mathrm{GtCO}_{2}$ to $31.7 \mathrm{GtCO}_{2}$ and cancellation volumes from $12.2 \mathrm{GtCO}_{2}$ to $13.3 \mathrm{GtCO}_{2}$ (Fig. 3, E and $\mathrm{C})$. This underlines the robustness of our results regarding EUA prices, cumulative emissions and cancellation volumes w.r.t. assumptions on the availability of certain technologies, fuel prices and electricity demand growth. Especially the robustness to assumptions on the electricity demand growth is relevant in this context, as we do not consider the impact of abatement- or policy-driven electrification in the energy-intensive industry or other sectors. This robustness may be explained by the observation that the power sector evolves to a low-carbon system, dominated by renewable energy sources, in all considered scenarios, as we will expose in Section 5.2.2. As such, these changes in electricity demand have a limited impact on the emissions, hence, actions of the MSR. However, variations are to be observed in the emissions from the energy-intensive industry $\left(17.2 \mathrm{GtCO}_{2}\right.$ to $20.8 \mathrm{GtCO}_{2}$, Fig. 3, E-IND) and the power sector $\left(10.8 \mathrm{GtCO}_{2}\right.$ to $13.5 \mathrm{GtCO}_{2}$, Fig. 3, E-PS). The exploration of these $\mathrm{CO}_{2}$ emission displacements and their relation to changes in the power sector is the topic at hand in the next section.

\subsubsection{A more detailed overview of changes in the power sector}

As expected, policy scenarios that are characterized by high EUA prices, such as our reference scenario, exhibit (1) higher electricity prices and (2) lower REC prices (Fig. 4). High EUA prices trigger a change in the electricity generation mix (see further) and entail a cost for $\mathrm{CO}_{2}$-emitting electricity generation technologies, which is transferred to consumers via increased electricity prices, required for generators to recover their investment costs. These increased electricity prices, however, also depress the required support under the form of RECs to ensure cost-recovery for RES-based generators (see also Section 5.3).

Policy scenarios characterized by a high cummulative cap and low ETS prices, i.e., 'MSR2015' and 'MSR2018-LRF1.74' tolerate higher shares of $\mathrm{CO}_{2}$-intensive forms of electricity generation. Indeed, in these scenarios, the switch to natural gas, and subsequently, RES, is delayed. In 2030, lignite, coal and oil-fired electricity generation still account, on average, for $252 \mathrm{TWh}$ and $229 \mathrm{TWh}$, although in none of the considered cases new investment in these technologies occur. In contrast, in all other policy scenarios, the output of these technologies drops on average below 68 TWh by 2030. Similar trends are observed in the average output of gas-fired power plants, which ranges from 842 TWh ('MSR2018-RES50') to 1,427 TWh ('MSR2015'). Note that not considering the cancellation provision leads to higher fossil fuel shares, whereas more ambitious RES-targets lead to the opposite effect.

Policy scenarios 'MSR2018', 'MSR 2018-NC' and 'MSR 2018-RES50' are characterized by similar RES developments by 2030. On average, RES are responsible for 1,851 TWh in our reference policy scenario by 2030. Not considering the cancellation policy depresses EUA prices, which leads to somewhat slowed developments of RES. A stringent RES target ensures high volumes of RES-based generation, which range from 1,642 TWh to 2,002 TWh. 


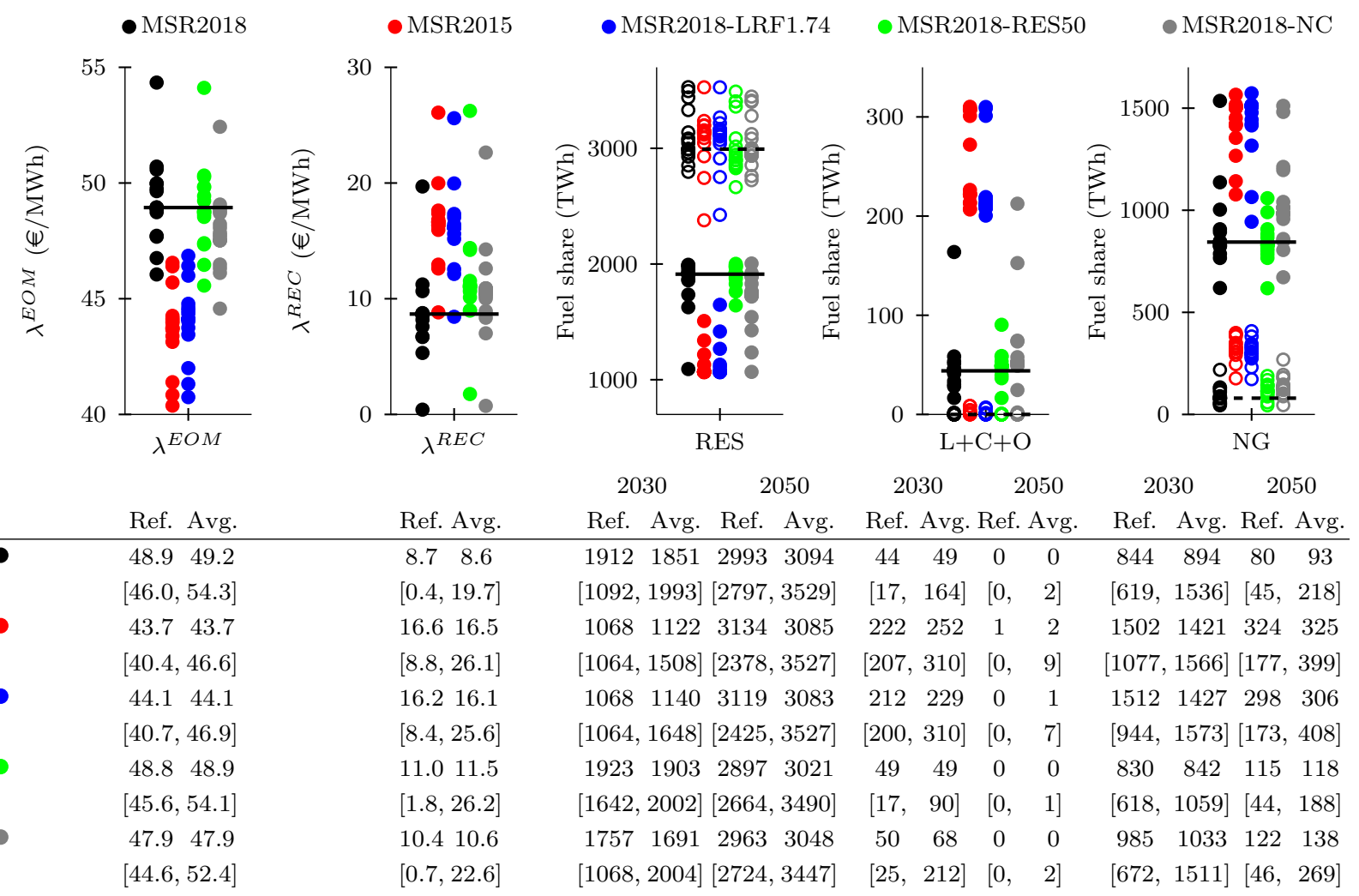

Figure 4. Share of lignite, coal and oil $(\mathrm{L}+\mathrm{C}+\mathrm{O})$, natural gas $(\mathrm{NG})$ and renewables (RES) in the power sector's fuel mix in 2030 and 2050; average electricity prices $\lambda_{y}^{\mathrm{EOM}}$ over the model horizon and average value of REC $\left(\lambda^{R E C}\right)$ over the period 2020-2030 in the different policy scenarios, as indicated by the colors of the markers. The solid markers indicate the fuel shares in 2030, whereas the white-filled markers correspond to those in 2050. The solid (2030) or dashed (2050) black line indicates the value in the reference scenario. The table below summarizes the results for the five selected indicators under reference assumptions ('Ref.'), averaged across the seventeen results per policy scenario ('Avg.'), the minimum and maximum value (intervals).

As expected, less electricity is generated from RES by 2030 in policy scenarios 'MSR2015' (1,122 TWh) and 'MSR2018-LRF1.74' (1,140 TWh).

Gas-fired electricity generation peaks between 2025 and 2030 in policy scenarios 'MSR2018', 'MSR2018-NC' and 'MSR2018-RES50'. In the last scenario, this peak is less pronounced, with gas-fired generation accounting for 618 to 1,059 TWh in 2030, whereas in our reference policy scenario, this ranges from 619 TWh to 1,536 TWh. In 2050, gas-fired generation is reduced to, on average, 93 TWh in the reference policy scenario. Similar volumes are observed in policy scenarios 'MSR2018-NC' and 'MSR2018-RES50'. In policy scenarios 'MSR2018LRF1.74' and 'MSR2015', gas-fired electricity generation remains above 300 TWh in 2050.

Remarkably, all policy scenarios are characterized by similar RES-based electricity generation volumes in 2050: on average, RES-based generation ranges from 3,021 TWh ('RES2018RES50') to 3,094 TWh ('MSR2018'). This similar trend is triggered by the falling investment costs for renewable electricity generation technologies and declining $\mathrm{CO}_{2}$ emissions cap, regardless of the MSR design, 2030 RES target or LRF. 
Furthermore, within each policy scenario, the sensitivity analysis reveals significant variations in fuel shares, electricity and REC prices depending on our assumptions w.r.t. key parameters. Four pronounced effects may be distinguished. First, the discount rate affects the EUA price (Section 5.2.1), which in turn affects electricity and REC prices, as well as the fuel shares in the electricity sector. High discount rates depress EUA prices in the short run, which in turn allows for higher shares of lignite-, coal-, gas- and oil-fired generation and less RES-based electricity generation up to 2030. The switch from lignite and coal to natural gas is delayed and less pronounced. In the long run, fuel shares are however typically not significantly affected. Second, higher natural gas prices tolerate elevated ligniteand coal-fired generation in 2030, but also promote the uptake of renewables. Third, the reaction of the industry to EUA prices mostly impacts the abatement in the power sector on the short term. For example, in 2030, lower abatement costs, hence higher abatement rates, in the energy-intensive industry result in a higher share of $\mathrm{CO}_{2}$-intensive forms of electricity generation. In 2050, lower abatement in the energy-intensive industry triggers a displacement of new nuclear capacity by gas-fired capacity. Last, in policy scenarios characterized by low EUA prices ('MSR2018-LRF1.74' and 'MSR2015'), the RES target in 2030 is binding in all scenarios, except those characterized by (1) high gas prices, (2) low discount rates or (3) accelerated decreases in investment costs of wind and solar power, which all promote RES-based generation.

\subsection{Impact on total costs}

To properly interpret these changes in, i.a., electricity, EUA and REC prices, one has to compare the overall change in total costs induced by changing policies. In this paper, we approximate changes in total cost by calculating the change in overall investment and operating costs required to meet the demand for electricity and policy targets:

$$
\left.T C=\sum_{y \in \mathcal{Y}} A_{y}^{S P} \cdot \sum_{p \in \mathcal{P}} \sum_{d \in \mathcal{D}} W_{d} \cdot \sum_{h \in \mathcal{H}} V C_{p}^{\mathrm{C}} \cdot g_{y, d, h, p}^{\mathrm{C} *}+\sum_{p \in \mathcal{P}} I C_{p}^{\mathrm{C}} \cdot c p_{y, p}^{\mathrm{C} *}+\sum_{r \in \mathcal{R}} I C_{r}^{\mathrm{R}} \cdot c p_{y, r}^{\mathrm{R} *}+\int_{e_{y}^{\mathrm{I} *}}^{e^{\mathrm{I}}} \mathcal{F}^{-1}\left(e_{y}^{\mathrm{I}}\right)\right]
$$

in which we use an asterisk to indicate the values of the decision variables in the equilibrium. The first term $\sum_{p \in \mathcal{P}} \sum_{d \in \mathcal{D}} W_{d} \sum_{h \in \mathcal{H}} V C_{p}^{\mathrm{C}} g_{y, d, h, p}^{\mathrm{C} *}$ corresponds to the estimated generation costs in the power system. The second and third term are the investment costs in conventional $\sum_{p \in \mathcal{P}} I C_{p}^{\mathrm{C}} \cdot c p_{y, p}^{\mathrm{C} *}$ and renewable generation capacity $\sum_{r \in \mathcal{R}} I C_{r}^{\mathrm{R}} \cdot c p_{y, r}^{\mathrm{R} *}$. The last term indicates the abatement cost in the energy-intensive industry, calculated as the integral under the marginal abatement cost curve: $\int_{e_{y}^{\mathrm{I} * 17}}^{e_{217}^{\mathrm{I}}} \mathcal{F}^{-1}\left(e_{y}^{\mathrm{I}}\right)$. Note that we do not account for the salvage value of generation capacity investments and that costs are discounted from a social planner perspective, i.e., using $3.5 \%$ as discount rate $\left(A_{y}^{S P}=1 /(1+0.035)^{y-1}\right)$.

In Fig. 5, we summarize the result of this calculation, by plotting the total cost of each policy scenario under different technology, demand and discount rate assumptions as a function of the cumulative $\mathrm{CO}_{2}$ emissions over the period 2017-2061. In the discussion above, we extensively focused on the underlying drivers for the variations in the observed $\mathrm{CO}_{2}$ emissions under the same and different policy designs, here visualized by the width of 


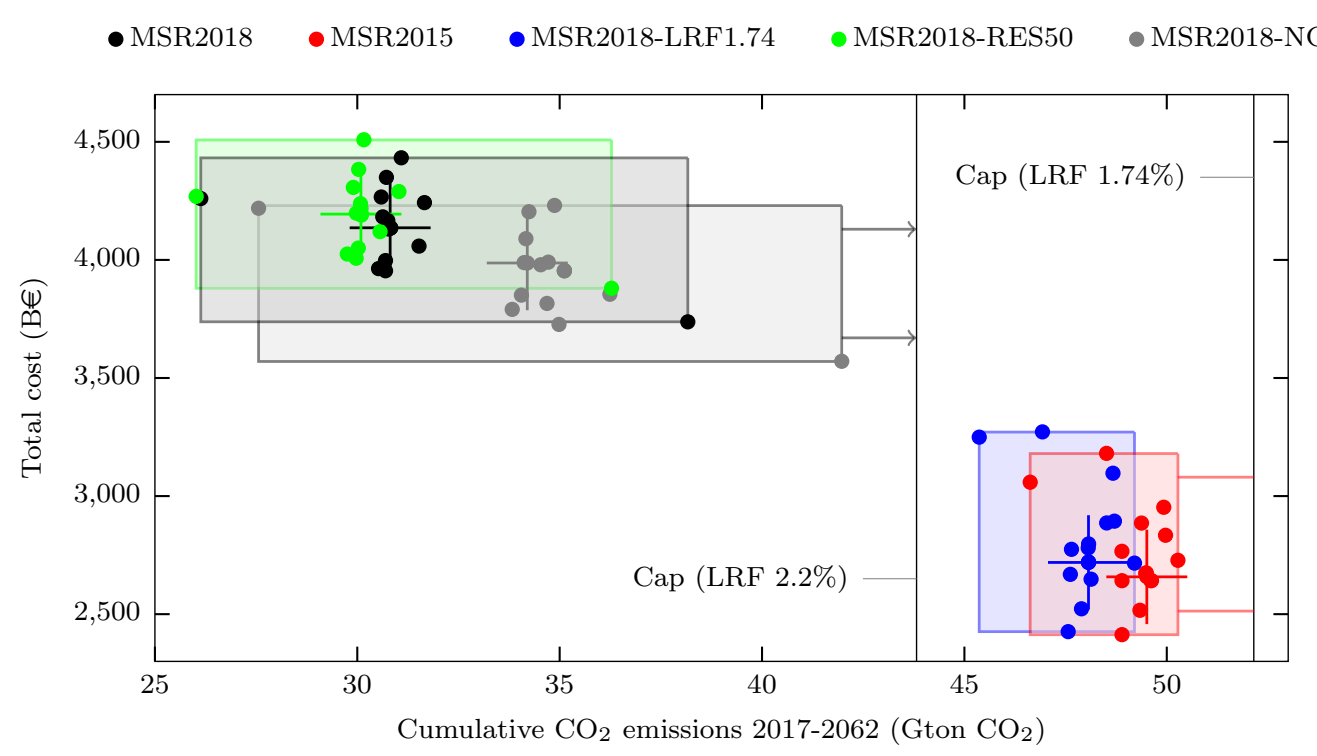

Figure 5. The total cost of a policy scenario, under different sets of assumptions, versus the cumulative $\mathrm{CO}_{2}$ emissions over the period 2017-2061. The crosses indicate the total cost and cumulative emissions under reference assumptions, whereas the shaded areas indicate the range of costs and $\mathrm{CO}_{2}$ emissions observed in the sensitivity analysis per policy scenario. The vertical lines indicate the cumulative cap, assuming a LRF of $1.74 \%$ or $2.2 \%$ as of 2021, including (i) backloaded and unallocated EUAs from the third phase of the EU ETS and (ii) the surplus at the end of 2016. Note that for policy scenarios 'MSR2015' and 'MSR2018-NC' the difference between the cap and the observed cumulative $\mathrm{CO}_{2}$ emissions over the period 2017-2061 is still stored in the MSR at the end of 2061, whereas in the other policy scenarios, this volume is cancelled. The EUAs in the MSR at the end of 2061 will, in abscense of a cancellation policy in policy scenarios 'MSR2015' and 'MSR2018-NC', result in $\mathrm{CO}_{2}$ emissions in subsequent years, as indicated by the arrows.

the boxes. Note that current policies, compared to policy scenario 'MSR2015', lead to larger variations in observed $\mathrm{CO}_{2}$ emissions due to the cancellation policy and the self-reinforcing feedback effect between marginal abatement costs and cancellation volumes (Bruninx et al., 2019). In addition, recall that in policy scenarios without a cancellation policy, the difference between the $\mathrm{CO}_{2}$ emissions in the period 2017-2061 and the cap is stored in the MSR. In theory, these allowances will be made available after 2061, hence, result in $\mathrm{CO}_{2}$ emissions, as indicated by the arrows in Fig. 5. In what follows, however, we focus on how total costs differ within and between policy scenarios.

Considering the total cost under reference assumptions in each of the policy scenarios, the following observations can be made. First, the total cost of the 'MSR2018' scenario amounts to 4,136 $\mathrm{B} €$, which is to be compared to $2,658 \mathrm{~B} €$ in the 'MSR2015' policy scenario. The difference in cost equals $1,477 \mathrm{~B} €$. The cumulative $\mathrm{CO}_{2}$ emissions are, however, 18,694 $\mathrm{MtCO}_{2}$ (21,338 $\mathrm{MtCO}_{2}$ compared to the cumulative cap in the 'MSR2015' scenario) higher in the last case. The additional abatement caused by the strengthened MSR, the increased LRF and 2030 RES target of $32 \%$, hence, comes at a cost of $79.0 € / \mathrm{tCO}_{2}\left(69.2 € / \mathrm{tCO}_{2}\right.$ considering the cumulative cap in the 'MSR2015' scenario). Similar relative cost differences (expressed in $€ / \mathrm{tCO}_{2}$, considering $\mathrm{CO}_{2}$ emissions in the period 2017-2061) are observed 
between our reference policy scenario 'MSR2015' and policy scenarios 'MSR2018-NC' (83.2 $\left.€ / \mathrm{tCO}_{2}\right)$ and 'MSR2018-RES50' (73.1 $\left.€ / \mathrm{tCO}_{2}\right)$. Note that average, relative abatement costs are higher for the less ambitious no-cancellation policy scenario. Considering that in policy scenarios 'MSR2015' and 'MSR2018-NC', the MSR is not depleted by the end of 2061 and that these EUAs will result in $\mathrm{CO}_{2}$ emissions, relative abatement costs w.r.t. the cumulative cap in each scenario amount to $159.4 € / \mathrm{tCO}_{2}$. Comparing policy scenario 'MSR2015' with policy scenario 'MSR2018-LRF1.74' reveals a relative total cost difference of $42.3 € / \mathrm{tCO}_{2}$ or $14.9 € / \mathrm{tCO}_{2}$ if one considers the cumulative cap in policy scenario 'MSR2015'. As discussed above, the strengthening the MSR without increasing the LRF leads to limited reductions in the available EUAs to the market $\left(4.1 \mathrm{GtCO}_{2}\right)$, which can be offset by cheap investments in abatement measures.

The sensitivity analysis reveals that the variations in estimated total costs are similar in all policy scenarios: $629 \mathrm{~B} €$ ('MSR2018-RES50') to $845 \mathrm{~B} €$ ('MSR2018-LRF1.74'). Relative to the total cost under reference assumptions, policy scenarios 'MSR2018', 'MSR2018RES50' and 'MSR2018-NC' show a variation in total cost of $15.0 \%$ to $16.8 \%$, whereas for policy scenarios 'MSR2015' and 'MSR2018-LRF1.74' this relative difference may amount to $31.1 \%$. The drivers of high cost outcomes are, in order of importance, high demand growth, slow reduction in the investment cost of wind power, not allowing new nuclear power plants, low discount rates and high abatement costs in industry. High discount rates, low abatement costs in industry and accelerated wind power investment cost reductions lead to low total cost outcomes. These cost differences are in part driven by the direct impact of the change in parameters (e.g., higher investment costs for wind power results in higher total costs) and in part by the varying stringency of the cumulative cap (i.e., a smaller cumulative cap is more expensive to meet). In policy scenarios with a cancellation provision, the stringency of the cumulative cap is determined by the self-reinforcing feedback effect of today's perception of future abatement costs on the cancellation volume. Indeed, as these parameters affect today's perception of future abatement costs, they affect the profitability of banking allowances today, which in turn determines the surplus, absorbed and cancelled volume of allowances. This explains how discount rates affect the total cost of meeting the policy. In policy scenarios without a cancellation provision, a number of allowances may still be stored in the MSR at the end of our model horizon, limiting cumulative emissions in the period 2019-2061.

\section{Policy Implications}

As in any model, assumptions and projections of uncertain input parameters, such as fuel prices, are required. Hence, our results should not be interpreted as a forecast of what energy, REC or EUA prices will be, but rather as a comparative, what-if analysis of several hypothetical policy scenarios. Such an analysis allows quantifying the order of magnitude of the impact of certain policy measures such as, e.g., the implementation of the MSR and the choice its design parameters. Below, we discuss the policy implications of our work.

The overall long-term trends in the power sector are driven by the decreasing greenhouse gas emissions cap, changes in fuel costs and falling investment costs for RES-based technolo- 
gies, independent from the implementation of a (strengthened) MSR and an increase in the LRF. However, the 2018 legislative package has been shown to (1) accelerate the phase-out of coal and lignite and the adoption of natural gas as a transition fuel to renewables and (2) significantly reduce $\mathrm{CO}_{2}$ emissions. The recently observed EUA price increase (Fig. 1) seems to indicate that the ETS reform has persuaded the energy-intensive industry and the power sector of the future scarcity of EUAs (Section 1). Note that this EUA price increase is exactly in line with our model results, i.e., an increase from $6.8 € / \mathrm{tCO}_{2}$ to $27.4 € / \mathrm{tCO}_{2}$ in 2019 .

However, several critical remarks can be made on the current policy design. First, the impact of the MSR is highly dependent on other policies, such as the LRF or RES targets, due to the self-reinforcing feedback effect between today's perception of current and future marginal abatement costs and the cancellation volume (Bruninx et al., 2019). This is most apparent in our 'MSR2018-LRF1.74' scenario, which illustrates that the strengthened MSR alone is expected to reduce emissions less than in a policy scenario with a LRF of $2.2 \%$ without an MSR. Besides EU policy decisions, other evolutions, such as nuclear, coal and lignite phase-outs affect the impact of the MSR and the achieved $\mathrm{CO}_{2}$ emission reductions. Hence, the effective $\mathrm{CO}_{2}$ emissions allowed under the ETS are no longer fixed, which may create uncertainty for investors in the power sector and energy-intensive industry and makes it impossible to set clear $\mathrm{CO}_{2}$ emission reduction targets. In addition, the design of complementary climate policies, such as RES targets and support, becomes increasingly complicated, as one needs to account for the secondary effect on the effective cumulative $\mathrm{CO}_{2}$ emissions cap in the ETS (Perino et al., 2019; Bruninx et al., 2019). Second, the decision to place back-loaded and unallocated EUAs in the MSR has no impact on the net supply of EUAs. Indeed, in all our results under policy scenario 'MSR2018', the volume of allowances cancelled in 2023 exceeds the volume of back-loaded and unallocated EUAs placed in the MSR, as banking of allowances (hence, high TNAC levels) persist well into the 2030's. One could wonder whether cancelling these back-loaded and unallocated allowances, i.e., explicitly instead of implicitly tightening the emissions cap, would not provide a stronger signal to the sectors covered in the ETS. Last, the metric on which the actions of the MSR are based, i.e., the TNAC, is not in line with the effective surplus available to market participants. Indeed, as aviation is currently excluded from the calculation of the TNAC and this sector buys EUAs to compensate for emissions above its annual cap, the effective surplus in the market is below the TNAC. ${ }^{10}$ Considering the expected growth in $\mathrm{CO}_{2}$ emissions from aviation, the difference between the TNAC and the effective surplus in the market is only expected to grow (Sandbag, 2017a).

In light of these challenges, one could wonder if explicitly strengthening the LRF (beyond the current increase from $1.74 \%$ to $2.2 \%$ ) would not have provided a clearer message to energy-intensive industry and the power sector. Figure 6 shows the equivalent LRF as of 2020 that allows the same cumulative $\mathrm{CO}_{2}$ emissions over the period 2017-2061 in all policy 


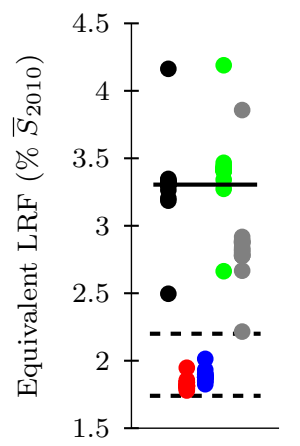

\begin{tabular}{lcccc} 
& \multicolumn{4}{c}{ Equivalent Linear Reduction Factor $\left(\% \bar{S}_{2010}\right)$} \\
& Reference assumptions & Average & Minimum & Maximum \\
\hline - MSR2018 & 3.30 & 3.30 & 2.50 & 4.16 \\
- MSR2015 & 1.81 & 1.82 & 1.78 & 1.95 \\
- MSR2018-LRF1.74 & 1.88 & 1.89 & 1.82 & 2.01 \\
- MSR2018-RES50 & 3.41 & 3.41 & 2.66 & 4.19 \\
- MSR2018-NC & 2.88 & 2.85 & 2.22 & 3.86
\end{tabular}

Figure 6. The equivalent LRF as of 2020 that allows the same cumulative $\mathrm{CO}_{2}$ emissions over the period 2017-2061 in each of the policy scenarios, considering all parameter sets. Different colors represent the policy scenarios, whereas the solid black line indicates the equivalent LRF in policy scenario 'MSR2018' under reference assumptions. The dashed lines indicate the $1.74 \%$ and $2.2 \%$ LRF. The equivalent LRF is calculated via Eq. (20) in Footnote 23.

scenarios and across all parameter sets. ${ }^{23}$ For example, in policy scenario 'MSR2018' under reference assumptions, the equivalent LRF equals $72.7 \mathrm{MtCO}_{2} /$ year or $3.3 \%$ of the 2010 emissions cap, assuming backloaded and unallocated allowances from Phase 3 are not made available to the market. Figure 6 once more illustrates the large uncertainty on the effective cumulative $\mathrm{CO}_{2}$ emissions and the dependency of the effect of the current policy design on other evolutions in the power sector, energy-intensive industry and complementary climate policies. Enforcing these equivalent LRFs would, however, ensure that the tolerated $\mathrm{CO}_{2}$ emissions would be known ex-ante and with certainty, without the need to introduce an MSR and a cancellation policy. Moreover, the design of complementary climate and energy policies, e.g., of individual member states, would not affect this cap, simplifying their design.

\section{Conclusions \& future work}

In the recent past, the EU ETS failed to provide a sufficiently strong price signal to drive investments in carbon abatement. Therefore, Europe recently decided to strengthen the foreseen MSR and increase the LRF from $1.74 \%$ to $2.2 \%$. This MSR will absorb (a part of) the excess of EUAs, in order to limit the oversupply of EUAs and increase their price. In addition, as of 2023, the amount of EUAs in the MSR is limited to the amount of EUAs auctioned in the previous year, implying cancellation of 'excess' allowances from the system.

${ }^{23}$ The required equivalent LRF, expressed in $\mathrm{MtCO}_{2}$, may be calculated using the following formula:

$$
L R F=\frac{\bar{S}_{2020}^{2}}{2 \cdot\left[\sum_{y=2017}^{2061}\left(e_{y}^{\mathrm{I}}+e_{y}^{\mathrm{PS}}\right)-\sum_{y=2017}^{2019} \overline{S_{y}}\right]-\bar{S}_{2020}}
$$

in which $\bar{S}_{2020}$ is the emissions cap in 2020, the sum $\sum_{y=2017}^{2061}\left(e_{y}^{\mathrm{I}}+e_{y}^{\mathrm{PS}}\right)$ represents the tolerated cumulative $\mathrm{CO}_{2}$ emissions over the studied period and $\sum_{y=2017}^{2019} \overline{S_{y}}$ is the cumulative supply of EUAs in the period 2017-2019, including the current surplus in the market. 
The market's reaction to, i.a., the foreseen implementation of this system led to a signficant EUA price increase, as discussed in Section 1.

In this contribution, we put forward an extensive analysis of the long term impact of the introduction of the MSR on EUA prices, $\mathrm{CO}_{2}$ emissions and investments in the power sector and industry. To this end, we develop a novel equilibrium model, representing the long-term interaction between the electric power sector, the energy-intensive industry, the energy-only electricity market and the EU ETS. This model is formulated as a large-scale MCP, with a focus on the electric power sector.

Comparing the results of simulations considering the design of the ETS before and after the 2018 reform, we observe a threefold increase in EUA prices from $6.8 € / \mathrm{tCO}_{2}$ to 27.4 $€ / \mathrm{tCO}_{2}$ in 2019, in line with the actual EUA price increase observed in 2018 and 2019. Cumulative $\mathrm{CO}_{2}$ emissions under the current policies may amount to $30.8 \mathrm{GtCO}_{2}$, hence $41 \%$ or $21.3 \mathrm{GtCO}_{2}$ below the cumulative cap before the strengthening of the ETS $\left(52.2 \mathrm{GtCO}_{2}\right)$. Around $40 \%$ of this decrease $\left(8.3 \mathrm{GtCO}_{2}\right)$ is due to the increased linear reduction factor and $60 \%$ due to the cancellation policy $\left(13 \mathrm{GtCO}_{2}\right)$. The strengthened MSR and the increase in the LRF advance and amplify natural gas-coal fuel switching and RES investments in the power sector, as well as abatement in the energy-intensive industry. This results in an average increase of $5.3 € / \mathrm{MWh}$ in average electricity prices and an average decrease of 7.9 $€ / M W h$ in REC prices. We also find that these $\mathrm{CO}_{2}$ emission reductions come at a cost of $79 € / \mathrm{tCO}_{2}$. A sensitivity analysis on our assumption on key parameters reveals, however, that the impact of the MSR on $\mathrm{CO}_{2}$ emissions is strongly dependent on other policies, such as allowing new nuclear capacity or not, and the evolution of investment costs of, e.g., wind power. This dependency is driven by the self-reinforcing feedback effect that exists between today's perception of current and future marginal abatement costs and the cancellation volume (Bruninx et al., 2019): policies that increase the marginal cost of future abatement provide an incentive for banking today, hence increase the surplus allowances, the volume of allowances absorbed and, ultimately, cancelled by the MSR. Cumulative emissions in the period 2017-2061 vary between $26.1 \mathrm{GtCO}_{2}$ and $38.2 \mathrm{GtCO}_{2}$, which is to be compared with the cumulative cap of $43.8 \mathrm{GtCO}_{2}(\mathrm{LRF} 2.2 \%)$ or $52.2 \mathrm{GtCO}_{2}(\mathrm{LRF} 1.74 \%)$. Studying various policy scenarios (i.e., the current design of the MSR, complemented with (i) a LRF of $1.74 \%$ post 2020, (ii) a 50\% RES target in the power sector in 2030 or (iii) without the cancellation provision) shows that it is the combination of the increase in LRF and cancellation provision of the MSR which drives the results. Indeed, with a LRF of $1.74 \%$, the MSR's cancellation policy would decrease emissions by 2.9 to $6.8 \mathrm{GtCO}_{2}$ compared to the cumulative cap $\left(52.2 \mathrm{GtCO}_{2}\right)$.

The dependency of the impact of the MSR on $\mathrm{CO}_{2}$ emissions on other, complementary climate and energy policies, as well as on developments in the power sector, complicates setting specific $\mathrm{CO}_{2}$ emission reduction targets and the design of the aforementioned complementary climate policies, such as RES targets and support. The ETS without MSR, but with a more stringent LRF, is less prone to such issues. As discussed in Section 6, the equivalent LRF post-2020 to reach the same cumulative $\mathrm{CO}_{2}$ emissions as under our reference assumptions in policy scenario 'MSR2018' without an MSR equals $72.7 \mathrm{MtCO}_{2} /$ year or $3.3 \%$ of the 2010 emissions cap. 
Future work may entail the inclusion of more detail in the operating costs and constraints in the power sector, enhancing the temporal and geographical resolution of the model and the abatement options in the energy-intensive industry. In the same vain, explicitly considering (1) the adoption of technologies such as electric vehicles, power-to-X and heat pumps or (2) the relation between abatement and electrification in the energy-intensive industry may further strengthen our analysis. Relaxing our assumptions of rationality (e.g., introducing myopia), free entry and perfect competition may lead to additional insights.

\section{Acknowledgements}

K. Bruninx is a post-doctoral research fellow of the Research Foundation - Flanders (FWO) at the University of Leuven and EnergyVille. His work was funded under postdoctoral mandates no. 12J3317N, sponsored by the Flemish Institute for Technological Research (VITO) and FWO, and no. 12J3320N, sponsored by FWO. The authors would like to thank H. Höschle (VITO) for his advice on the ADMM algorithm.

\section{Bibliography}

Agora Energiewende, 2016. Energy Transition in the Power Sector in Europe: State of Affairs in 2015. Tech. Report.

Beck, U., Kruse-Andersen, P., 2018. Endogenizing the cap in a cap-and-trade system: Assessing the agreement on eu ets phase 4. DORS Working Paper 2018:2.

Bel, G., Joseph, S., 2015. Emission abatement: Untangling the impacts of the EU ETS and the economic crisis. Energy Economics 49, 531-539.

Boyd, S., Parikh, N., Chu, E., Peleato, B., Eckstein, J., Jan. 2011. Distributed optimization and statistical learning via the alternating direction method of multipliers. Found. Trends Mach. Learn. 3 (1), 1-122.

BP, 2017. Statistical review of world energy. Tech. Report.

Bruninx, K., Ovaere, M., Gillingham, K., Delarue, E., 2019. The unintended consequences of the eu ets cancellation policy. KU Leuven Energy Institute Working Paper EN2019-11.

Capros, P., De Vita, A., Tasios, N., Siskos, P., Kannavou, M., Petropoulos, A., Evangelopoulou, S., Zampara, M., Papadopoulos, D., Nakos et al., C., Paroussos, L., Fragiadakis, K., Tsani, S., Karkatsoulis et al., P., Fragkos, P., Kouvaritakis et al., N., Höglund-Isaksson, L., Winiwarter, W., Purohit, P., Gomes-Sanabria, A., Frank, S., Forsell, N., Gusti, M., Havlík, P., Obersteiner, M., Witzke, H. P., Kesting, M., 2016. EU Reference Scenario 2016: Energy, Transport and GHG emissions trends to 2050. Tech. Report.

Carlén, B., Dahlqvist, A., Mandell, S., Marklund, P., 2018. EU ETS emissions under the Cancellation mechanism Effects of national measures. The National Institute of Economic Research Working paper No $151,1-20$.

Chappin, E. J., de Vries, L. J., Richstein, J. C., Bhagwat, P., Iychettira, K., Khan, S., 2017. Simulating climate and energy policy with agent-based modelling: The Energy Modelling Laboratory (EMLab). Environmental Modelling and Software 96, 421-431.

Chevallier, J., 2009. Carbon futures and macroeconomic risk factors: A view from the EU ETS. Energy Economics 31 (4), 614-625.

Cullen, J. A., Mansur, E. T., 2017. Inferring carbon abatement costs in electricity markets: A revealed preference approach using the shale revolution. American Economic Journal: Economic Policy 9 (3), $106-133$.

De Jonghe, C., Delarue, E., Belmans, R., D'haeseleer, W., 2009. Interactions between measures for the support of electricity from renewable energy sources and co2 mitigation. Energy Policy 37 (11), 4743 4752 . 
Delarue, E., D'haeseleer, W., 2008. Greenhouse gas emission reduction by means of fuel switching in electricity generation: Addressing the potentials. Energy Conversion and Management 49 (4), 843-853.

Delarue, E., Van den Bergh, K., 2016. Carbon mitigation in the electric power sector under cap-and-trade and renewables policies. Energy Policy 92, 34-44.

EEX, Last accessed: August 1, 2019. Emission Spot Primary Market Auction Report. Available online: https://www.eex.com/en/products/environmental-markets/emissions-auctions/archive.

Elia, 2017. Electricity scenarios for Belgium towards 2050 - Elias quantified study on the energy transition in 2030 and 2040. Tech. report.

ENTSO-E, 2018a. Ten year network development plan 2018 - maps \& data. Available online: http:// tyndp.entsoe.eu/maps-data/.

ENTSO-E, 2018b. Transparency platform. Available online: https://transparency.entsoe.eu/.

European Commission, 2015. EU ETS Handbook. DG Climate Action, 138.

European Commission, 2016. Eu reference scenario 2016 - energy, transport and ghg emissions - trends to 2050. Tech. Report.

European Commission, 2017. Communication from the Commission. Publication of the total number of allowances in circulation for the purposes of the Market Stability Reserve under the EU Emissions Trading System established by Directive 2003/87/EC. Tech. Report.

European Commission, 2018. Communication from the Commission. Publication of the total number of allowances in circulation in 2017 for the purposes of the Market Stability Reserve under the EU Emissions Trading System established by Directive 2003/87/EC. Tech. Report.

European Commission, 2019. Communication from the Commission. Publication of the total number of allowances in circulation in 2018 for the purposes of the Market Stability Reserve under the EU Emissions Trading System established by Directive 2003/87/EC. Tech. rep.

European Parliament \& Council, 2009. Directive 2009/28/EC of the European Parliament and of the Council of 23 April 2009 on the promotion of the use of energy from renewable sources and amending and subsequently repealing Directives 2001/77/EC and 2003/30/EC. Official Journal of the European Union 140, 1662.

European Parliament \& Council, 2018. Directive (EU) 2018/2001 of the European Parliament and of the Council of 11 December 2018 on the promotion of the use of energy from renewable sources . Official Journal of the European Union 328, 82-209.

European Union, 2015. Decision (EU) 2015/1814 of the European Parliment and of the Council of 6 October 2015 concerning the establishment and operation of a maerket stability reserve for the Union greenhouse gas emission trading scheme and amending Directive 2003/87/EC. Official Journal of the European Union $264,1-5$

European Union, 2018. Directive (EU) 2018/410 of the European Parliament and the Council of 14 March 2018 amending Directive 2003/87/EC to enhance cost-effective emission reductions and low-carbon investments, and Decision (EU) 2015/1814. Official Journal of the European Union 76, 3-27.

Hepburn, C., Neuhoff, K., Acworth, W., Burtraw, D., Jotzo, F., 2016. The economics of the EU ETS market stability reserve. Journal of Environmental Economics and Management 80, 1-5.

Hirth, L., 2013. The market value of variable renewables: The effect of solar wind power variability on their relative price. Energy Economics 38, 218 - 236.

URL http://www.sciencedirect.com/science/article/pii/S0140988313000285

Höschle, H., 2018. Capacity mechanisms in future electricity markets. Ph.D. thesis, KU Leuven.

Höschle, H., Le Cadre, H., Belmans, R., 2018. Inefficiencies caused by non-harmonized capacity mechanisms in an interconnected electricity market. Sustainable Energy, Grids and Networks 13, 29-41.

Höschle, H., Le Cadre, H., Smeers, Y., Papavasiliou, A., Belmans, R., 2017. Risk-aversion in Capacity Mechanisms Computing Stochastic Market Equilibria using ADMM. IEEE Transactions on Power Systems 33 (5), 4819-4830.

International Energy Agency (IEA), 2015. Projected costs of electricity generation. Tech. Report.

Koch, N., Fuss, S., Grosjean, G., Edenhofer, O., 2014. Causes of the EU ETS price drop: Recession, CDM, renewable policies or a bit of everything?-New evidence. Energy Policy 73, 676-685. 
Kollenberg, S., Taschini, L., 2016. Emissions trading systems with cap adjustments \$. Journal of Environmental Economics and Management 80, 20-36.

URL http://dx.doi.org/10.1016/j.jeem.2016.09.003

Landis, F., 2015. Final report on marginal abatement cost curves for the evaluation of the market stability reserve. ZEW-Dokumentation No. 15-01.

McKinsey \& Company, 2018. Decarbonization of industrial sectors: the next frontier.

Perino, G., 2018. New EU ETS Phase 4 rules temporarily puncture waterbed. Nature Climate Change 8 (4), 262-264.

Perino, G., Ritz, R. A., Van Benthem, A., 2019. Understanding overlapping policies: Internal carbon leakage and the punctured waterbed. EPRG Working Paper 1910 - Cambridge Working Paper in Economics 1920.

Perino, G., Willner, M., 2016. Procrastinating reform: The impact of the market stability reserve on the EU ETS. Journal of Environmental Economics and Management 80, 37-52.

Perino, G., Willner, M., 2017. EU-ETS Phase IV: allowance prices, design choices and the market stability reserve. Climate Policy 17 (7), 936-946.

Pettersson, F., Söderholm, P., Lundmark, R., 2012. Fuel switching and climate and energy policies in the European power generation sector: A generalized Leontief model. Energy Economics 34 (4), 1064-1073.

Pfenninger, S., Hawkes, A., Keirstead, J., 2014. Energy systems modeling for twenty-first century energy challenges. Renewable and Sustainable Energy Reviews 33, $74-86$.

URL http://www.sciencedirect.com/science/article/pii/S1364032114000872

Poncelet, K., Delarue, E., Dhaeseleer, W., 2020. Unit commitment constraints in long-term planning models: Relevance, pitfalls and the role of assumptions on flexibility. Applied Energy 258, 113843.

URL http://www.sciencedirect.com/science/article/pii/S0306261919315302

Poncelet, K., Höschle, H., Delarue, E., Virag, A., Dhaeseleer, W., 2017. Selecting representative days for capturing the implications of integrating intermittent renewables in generation expansion planning problems. IEEE Transactions on Power Systems 32 (3), 1936-1948.

Quemin, S., Trotignon, R., 2018. Intertemporal emissions trading and market design: an application to the eu ets. Centre for Climate Change Economics and Policy Working Paper 348 - Grantham Research Institute on Climate Change and the Environment Working Paper 316.

Richstein, J., 2015. Interactions between carbon and power markets in transition. Ph.D. thesis, TU Delft.

Richstein, J. C., Chappin, É. J., de Vries, L. J., 2015. The market (in-)stability reserve for EU carbon emission trading: Why it might fail and how to improve it. Utilities Policy 35, 1-18.

Rubin, J. D., 1996. A model of intertemporal emission trading, banking, and borrowing. Journal of Environmental Economics and Management 31 (3), 269-286.

Sandbag, 2017a. State of the EU Emissions Trading System 2017. Tech. report.

Sandbag, 2017b. The Three Billion Tonne Problem: ENVI's proposal alone won't fix the ETS. Tech. report.

Schopp, A., Acworth, W. W., Huppmann, D., Neuhoff, K., 2015. Modelling a Market Stability Reserve in Carbon Markets. DIW Discussion Papers 1483.

SolarEurope, 2018. Global solar market grows over $29 \%$ in 2017 with even more to come in 2018. Press release. Available online: http://solarpowereurope.org.

Van den Bergh, K., Delarue, E., D'haeseleer, W., dec 2013. Impact of renewables deployment on the CO2 price and the CO2 emissions in the European electricity sector. Energy Policy 63, 1021-1031.

Weigt, H., Ellerman, D., Delarue, E., 2013. CO2 abatement from renewables in the German electricity sector: Does a CO2 price help? Energy Economics 40, S149-S158.

WindEurope, 2018a. Offshore wind in europe - key trends and statistics 2017. Tech. Report.

WindEurope, 2018b. Wind in power 2017 - annual combined onshore and offshore wind energy statistics. Tech. Report. 


\section{Appendix A. ADMM: implementation \& performance}

The ADMM-based algorithm, summarized in the pseudo code below, will try to find the equilibrium based on a form of a 'tâtonnement', 'trial and error' or price adjustment procedure (Höschle, 2018). In each iteration, each agent receives the price of EUAs, RECs and electricity at each time step. Based on this information, each agent optimizes its investment and operating decisions. These decisions in turn affect market prices. By repeating this process, we attempt to determine the equilibrium prices at which none of the agents has an incentive to change its investment and operating decisions. As stated by Höschle (2018), there is no guarantee that the equilibrium found is unique. However, if the process converges, none of the agents has an incentive to deviate from its strategy and the market clearing conditions are satisfied.

Set $\lambda_{y, d, h}^{\mathrm{EOM}, 1}, \lambda_{y}^{\mathrm{REC}, 1}, \lambda_{y}^{\mathrm{ETS}, 1}=0, R^{\mathrm{EOM}, 1}, R^{\mathrm{ETS}, 1}, R^{\mathrm{REC}, 1}, R^{\mathrm{C}, 1}, R^{\mathrm{R}, 1}, R^{\mathrm{I}, 1}=2 \cdot \epsilon, i=1$

while $R^{\mathrm{EOM}, i}+R^{\mathrm{ETS}, i}+R^{\mathrm{REC}, i} \geq \epsilon$ or $R^{\mathrm{C}, i}+R^{\mathrm{R}, i}+R^{\mathrm{I}, i} \geq \epsilon$ do

(1) Solve agents problems, based on $\lambda_{y, d, h}^{\mathrm{EOM}, i}, \lambda_{y}^{\mathrm{REC}, i}, \lambda_{y}^{\mathrm{ETS}, i}$ :

$g_{y, d, h, p}^{\mathrm{C}, i}, b_{y, p}^{\mathrm{C}, i}=\operatorname{argmin}((\mathrm{A} .1)$ s.t. $(4)-(6))$

$g_{y, d, h, r}^{\mathrm{R}, i}, g_{y, r}^{\mathrm{R}, \mathrm{NB}, i}=\operatorname{argmin}((\mathrm{A} .2)$ s.t. $(8)-(10))$

$b_{y}^{\mathrm{I}, i}=\operatorname{argmin}((\mathrm{A} .3)$ s.t. $(12)-(14))$

(2) Update supply of allowances, considering MSR actions in each year $y$ according to Algorithm 2

(3) Update residuals: $R^{\mathrm{EOM}, i+1}, R^{\mathrm{ETS}, i+1}, R^{\mathrm{REC}, i+1}, R^{\mathrm{C}, i+1}, R^{\mathrm{R}, i+1}, R^{\mathrm{I}, i+1}$ according to Eq. (A.4)-(A.9)

(4) Update prices: $\lambda_{y, d, h}^{\mathrm{EOM}, i+1}, \lambda_{y}^{\mathrm{REC}, i+1}, \lambda_{y}^{\mathrm{ETS}, i+1}$ according to Eq. (A.10)- (A.12) $i=i+1$

end

Algorithm 1: Pseudo-code of the ADMM algorithm used to find the equilibrium between conventional generating companies, renewable generating companies and the energyintensive industry under the EU ETS, based on Höschle (2018).

In each step, we first update the agents decisions, based on the remaining imbalances, decisions in the previous iteration and the current prices $\lambda_{y, d, h}^{\mathrm{EOM}, i}, \lambda_{y}^{\mathrm{REC}, i}$ and $\lambda_{y}^{\mathrm{ETS}, i}$. Second, we update the net supply of allowances according to the MSR actions, based on the estimated emissions in this iteration (Algorithm 2). Third, the primal residuals $R^{\mathrm{EOM}, i}, R^{\mathrm{REC}, i}$ and $R^{\mathrm{ETS}, i}$ and the dual residuals $R^{\mathrm{C}, i}, R^{\mathrm{R}, i}$ and $R^{\mathrm{I}, i}$ are calculated (Eq. (A.4)-(A.9)). Last, prices are updated, depending on the remaining imbalances on the market clearing conditions (Eq. $($ A.10) - (A.12)). This process is repeated until the primal and dual residuals satisify a predefined stopping criterion $\epsilon$, which is defined as $\delta \sqrt{\left(N^{C}+N^{R}+1+1\right) \cdot N^{Y} \cdot N^{D} \cdot N^{H}}$, following Höschle (2018). $\delta$ is the tolerance, set to $10^{-2}$ in all simulations. 
Appendix A.1. Step (1): Solve agents problems, based on $\lambda_{y, d, h}^{\mathrm{EOM}, i}, \lambda_{y}^{\mathrm{REC}, i}, \lambda_{y}^{\mathrm{ETS}, i}$

In order to limit the change in the strategy of the agents from one iteration to the next, the objective of the optimization problems (3)-(6), (7)-(10) and (11)-(14) are recast as minimization problems and complemented with a penalty term for each of their decision variables that appear in a market clearing condition. With superscript $i$ indicating the current iteration, objectives (3), (7) and (11) are replaced by:

$$
\begin{aligned}
\text { Min. } & -\sum_{y \in \mathcal{Y}} A_{y} \cdot\left[\sum_{d \in \mathcal{D}} W_{d} \cdot \sum_{h \in \mathcal{H}}\left(\lambda_{y, d, h}^{\mathrm{EOM}, i}-V C_{p}^{\mathrm{C}}\right) g_{y, d, h, p}^{\mathrm{C}, i}-\left(1-S V_{y, p}^{\mathrm{C}}\right) \cdot I C_{p}^{\mathrm{C}} \cdot c p_{y, p}^{\mathrm{C}, i}-\lambda_{y}^{\mathrm{ETS}, i} \cdot b_{y, p}^{\mathrm{C}, i}\right] \quad \text { (A.1) } \\
& +\frac{\rho}{2} \cdot \sum_{y \in \mathcal{Y}} A_{y} \cdot \sum_{d \in \mathcal{D}} W_{d} \cdot \sum_{h \in \mathcal{H}}\left[g_{y, d, h, p}^{\mathrm{C}, i}-g_{y, d, h, p}^{\mathrm{C}, i-1}+\frac{1}{N^{\mathrm{EOM}}}\left(\sum_{p \in \mathcal{P}} g_{y, d, h, p}^{\mathrm{C}, i-1}+\sum_{r \in \mathcal{R}} g_{y, d, h, r}^{\mathrm{R}, i-1}-D_{y, d, h}\right)\right]^{2} \\
& +\frac{\rho}{2} \cdot \sum_{y \in \mathcal{Y}} A_{y} \cdot\left[b_{y, p}^{\mathrm{C}, i}-b_{y, p}^{\mathrm{C}, i-1}+\frac{1}{N^{\mathrm{ETS}}}\left(S_{y}^{i}-\sum_{p \in \mathcal{P}} b_{y, p}^{\mathrm{C}, i-1}-b_{y}^{\mathrm{I}, i-1}\right)\right]^{2} \\
\text { Min. } & -\sum_{y \in \mathcal{Y}} A_{y} \cdot\left[\sum_{d \in \mathcal{D}} W_{d} \cdot \sum_{h \in \mathcal{H}} \lambda_{y, d, h}^{\mathrm{EOM}} \cdot g_{y, d, h, r}^{\mathrm{R}, i}+\lambda_{y}^{\mathrm{REC}, i} \cdot g_{y, r}^{\mathrm{R}, \mathrm{NB}, i}-\left(1-S V_{y, r}^{\mathrm{R}}\right) \cdot I C_{r}^{\mathrm{R}} \cdot c p_{y, r}^{\mathrm{R}, i}\right] \\
& +\frac{\rho}{2} \cdot \sum_{y \in \mathcal{Y}} A_{y} \cdot \sum_{d \in \mathcal{D}} W_{d} \cdot \sum_{h \in \mathcal{H}}\left[g_{y, d, h, p}^{\mathrm{R}, i}-g_{y, d, h, r}^{\mathrm{R}, i-1}+\frac{1}{N^{\mathrm{EOM}}}\left(\sum_{p \in \mathcal{P}} g_{y, d, h, p}^{\mathrm{C}, i-1}+\sum_{r \in \mathcal{R}} g_{y, d, h, r}^{\mathrm{R}, i-1}-D_{y, d, h}\right)\right]^{2} \\
& +\frac{\rho}{2} \cdot \sum_{y \in \mathcal{Y} \mid\left\{R T_{y}>0\right\}} A_{y} \cdot\left[g_{y, r}^{\mathrm{R}, \mathrm{NB}, i}-g_{y, r}^{\mathrm{R}, \mathrm{NB}, \mathrm{i}-1}+\frac{1}{N^{\mathrm{R}}+1}\left(\sum_{r \in \mathcal{R}} g_{y, r}^{\mathrm{R}, \mathrm{NB}, \mathrm{i}-1}-R T_{y}\right)\right]^{2}
\end{aligned}
$$

Min. $\sum_{y \in \mathcal{Y}} A_{y} \cdot \lambda_{y}^{\mathrm{ETS}, i} \cdot b_{y}^{\mathrm{I}, i}+\frac{\rho}{2} \cdot \sum_{y \in \mathcal{Y}} A_{y} \cdot\left[b_{y}^{\mathrm{I}, i}-b_{y}^{\mathrm{I}, i-1}+\frac{1}{N^{\mathrm{ETS}}}\left(S_{y}^{i}-\sum_{p \in \mathcal{P}} b_{y, p}^{\mathrm{C}, i-1}-b_{y}^{\mathrm{I}, i-1}\right)\right]^{2}$

$N^{\mathrm{EOM}}$ is the number of participants in the energy-only market $\left(N^{\mathrm{EOM}}=N^{\mathrm{P}}+N^{\mathrm{R}}+1\right)$. Similarly, $N^{\text {ETS }}$ is the number of participants in the ETS system $\left(N^{\text {ETS }}=N^{\mathrm{P}}+2\right)$.

Note that the penalty terms reduce to zero when (i) the agent does not deviate from its strategy in the previous iteration (e.g., $g_{y, d, h, p}^{\mathrm{C}, i}=g_{y, d, h, p}^{\mathrm{C}, i-1}$ ) and (ii) the residual imbalance on the market reduces to zero (e.g., $\left.\sum_{p \in \mathcal{P}} g_{y, d, h, p}^{\mathrm{C}, i-1}+\sum_{r \in \mathcal{R}} g_{y, d, h, p}^{\mathrm{C}, i-1}-D_{y, d, h}=0\right)$. In other words, the penalty terms reduce to zero if an equilibrium is reached.

\section{Appendix A.2. Step (2) Update supply of allowances, considering MSR actions}

Given the emissions in the current iteration, one may calculate the TNAC at the end of each year. Given this metric for the surplus, the actions of the MSR (i.e., intake, outflow and/or cancellation) may be obtained, following the rules governing the MSR (Table 2). The different steps of this procedure are summarized in Algorithm 2. 
Set $y=2017$

\section{while $y \in \mathcal{Y}$ do}

Set $m=1$

while $m \in \mathcal{M}$ do

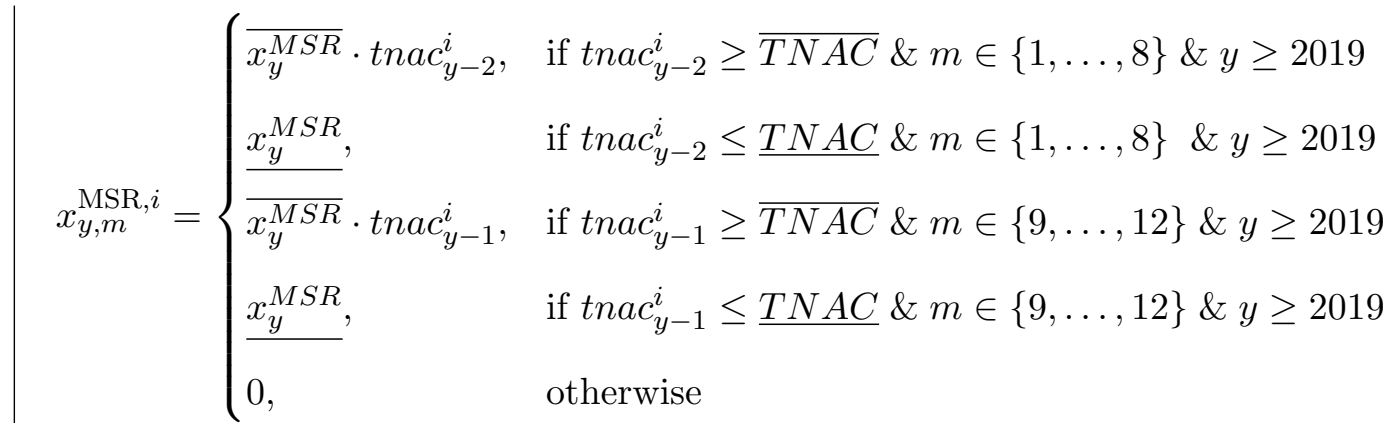

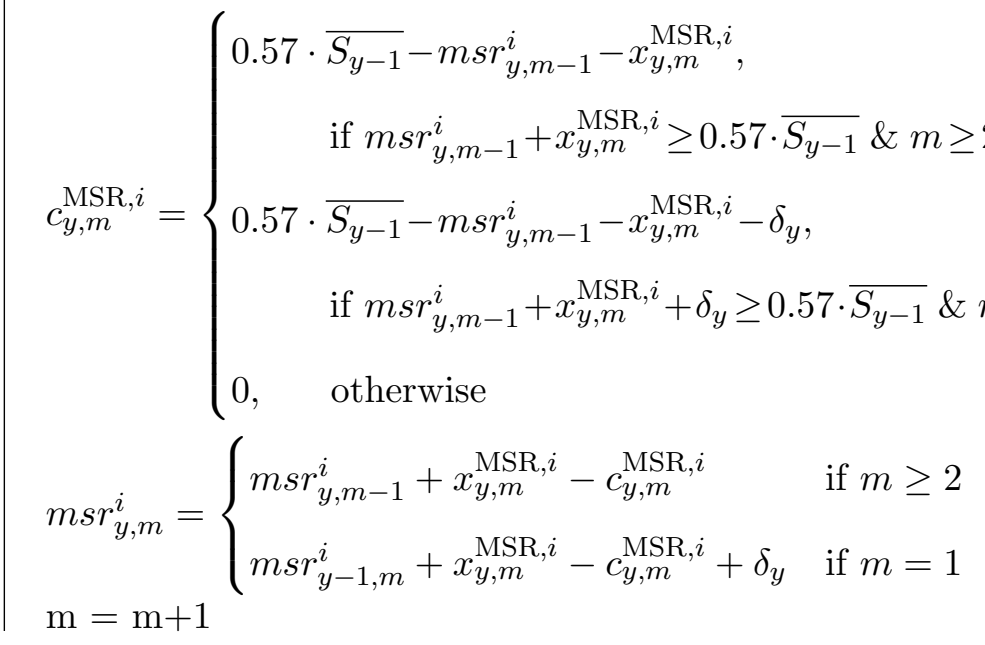

end

$$
\begin{aligned}
& \operatorname{tnac}_{y}^{i}=\sum_{y^{*}=1}^{y}\left[\overline{S_{y^{*}}}+\delta_{y^{*}}-\sum_{d \in \mathcal{D}} W_{d} \cdot \sum_{h \in \mathcal{H} p \in \mathcal{P}} C I_{p}^{\mathrm{C}} \cdot g_{y^{*}, d, h, p}^{\mathrm{C}, i}-e_{y^{*}}^{\mathrm{I}, i}-\sum_{m \in \mathcal{M}} c_{y^{*}, m}^{\mathrm{MSR}, i}-m s r_{y, 12}^{i}\right] \\
& S_{y}^{i+1}=\overline{S_{y}}-\sum_{m \in \mathcal{M}} x_{y, m}^{\mathrm{MSR}, i} \\
& \mathrm{y}=\mathrm{y}+1
\end{aligned}
$$

end

Algorithm 2: Pseudo-code describing the functioning of the MSR. Superscript $i$ refers to the iteration of the ADMM algorithm.

\section{Appendix A.3. Step (3): Update primal $\mathcal{E}$ dual residuals}

The primal residuals $R^{\mathrm{EOM}, i}, R^{\mathrm{REC}, i}$ and $R^{\mathrm{ETS}, i}$, i.e, the imbalances on the market clearing conditions, and the dual residuals $R^{\mathrm{C}, i}, R^{\mathrm{R}, i}$ and $R^{\mathrm{I}, i}$, as a measure of the change in the value of the decision variables from one iteration to the next, are calculated following Höschle (2018). Note that the primal ETS imbalance is governed by (i) the imbalance between demand and supply in each year and (ii) the difference between in supply of allowances between iterations due to the MSR actions. 


$$
\begin{aligned}
& R^{\mathrm{EOM}, i+1}=\sqrt{\sum_{y \in \mathcal{Y}} \sum_{d \in \mathcal{D}} \sum_{h \in \mathcal{H}}\left[\sum_{p \in \mathcal{P}} g_{y, d, h, p}^{\mathrm{C}, i}+\sum_{r \in \mathcal{R}} g_{y, d, h, r}^{\mathrm{R}, i}-D_{y, d, h}\right]^{2}} \\
& R^{\mathrm{ETS}, i+1}=\sqrt{\sum_{y \in \mathcal{Y}}\left[S_{y}^{i}-\sum_{p \in \mathcal{P}} b_{y, p}^{\mathrm{C}, i}-b_{y}^{\mathrm{I}, i}\right]^{2}}+\sqrt{\sum_{y \in \mathcal{Y}}\left[S_{y}^{i+1}-S_{y}^{i}\right]^{2}} \\
& R^{\mathrm{REC}, i+1}=\sqrt{\sum_{y \in \mathcal{Y} \mid\left\{R T_{y}>0\right\}}\left[\sum_{r \in \mathcal{R}} g_{y, r}^{\mathrm{R}, \mathrm{NB}, i}-R T_{y}\right]^{2}} \\
& R_{p}^{\mathrm{C}, i}=\rho \cdot \sqrt{\sum_{y \in \mathcal{Y}}\left[\left(b_{y, p}^{\mathrm{C}, i}-\chi_{y}^{\mathrm{ETS}, i}\right)-\left(b_{y, p}^{\mathrm{C}, i-1}-\chi_{y}^{\mathrm{ETS}, i-1}\right)\right]^{2}} \\
& +\rho \cdot \sqrt{\sum_{y \in \mathcal{Y}} \sum_{d \in \mathcal{D}} \sum_{h \in \mathcal{H}}\left[\left(g_{y, d, h, p}^{\mathrm{C}, i}-\chi_{y, d, h}^{\mathrm{EOM}, i}\right)-\left(g_{y, d, h, p}^{\mathrm{C}, i-1}-\chi_{y, d, h}^{\mathrm{EOM}, i-1}\right)\right]^{2}} \\
& \text { with } \chi_{y}^{\mathrm{ETS}, i}=\frac{1}{N^{\mathrm{ETS}}}\left(\sum_{p \in \mathcal{P}} b_{y, p}^{\mathrm{C}, i}+b_{y}^{\mathrm{I}, i}\right) \text { and } \chi_{y, d, h}^{\mathrm{EOM}, i}=\frac{1}{N^{\mathrm{EOM}}}\left(\sum_{p \in \mathcal{P}} g_{y, d, h, p}^{\mathrm{C}, i}+\sum_{r \in \mathcal{R}} g_{y, d, h, r}^{\mathrm{R}, i}\right) \\
& R_{r}^{\mathrm{R}, i+1}=\rho \cdot \sqrt{\sum_{y \in \mathcal{Y} \mid\left\{R T_{y}>0\right\}}\left[\left(g_{y, r}^{\mathrm{R}, \mathrm{NB}, i}-\chi_{y}^{\mathrm{REC}, i}\right)-\left(g_{y, r}^{\mathrm{R}, \mathrm{NB}, i-1}-\chi_{y}^{\mathrm{REC}, i}\right)\right]^{2}} \\
& +\rho \cdot \sqrt{\sum_{y \in \mathcal{Y}} \sum_{d \in \mathcal{D}} \sum_{h \in \mathcal{H}}\left[\left(g_{y, d, h, r}^{\mathrm{R}, i}-\chi_{y, d, h}^{\mathrm{EOM}, i}\right)-\left(g_{y, d, h, r}^{\mathrm{R}, i-1}-\chi_{y, d, h}^{\mathrm{EOM}, i-1}\right)\right]^{2}} \\
& \text { with } \chi_{y}^{\mathrm{REC}, i}=\frac{1}{N^{\mathrm{R}}+1} \sum_{r \in \mathcal{R}} g_{y, r}^{\mathrm{R}, \mathrm{NB}, i} \\
& R^{\mathrm{I}, i+1}=\rho \cdot \sqrt{\sum_{y \in \mathcal{Y}}\left[\left(b_{y}^{\mathrm{I}, i}-\chi_{y}^{\mathrm{ETS}, i}\right)-\left(b_{y}^{\mathrm{I}, i-1}-\chi_{y}^{\mathrm{ETS}, i-1}\right)\right]^{2}}
\end{aligned}
$$

\section{Appendix A.4. Step (4): Update prices}

For the energy only market, the price update reads, with $\rho$ a parameter controlling the 'step size' of the update:

$$
\forall y \in \mathcal{Y}, \forall d \in \mathcal{D}, \forall \in \mathcal{H}: \lambda_{y, d, h}^{\mathrm{EOM}, i+1}=\lambda_{y, d, h}^{\mathrm{EOM}, i}-\rho \cdot\left(\sum_{p \in \mathcal{P}} g_{y, d, h, p}^{\mathrm{C}, i}+\sum_{r \in \mathcal{R}} g_{y, d, h, r}^{\mathrm{R}, i}-D_{y, d, h}\right)
$$

We define the following price update strategy for EUAs:

$$
\forall y \in \mathcal{Y}: \lambda_{y}^{\mathrm{ETS}, i+1}=\lambda_{y}^{\mathrm{ETS}, i}-\frac{\rho}{8760}\left(S_{y}^{i+1}-\sum_{p \in \mathcal{P}} b_{y, p}^{\mathrm{C}, i}-b_{y}^{\mathrm{I}, i}\right),
$$

$S_{y}^{i+1}$ is the net supply of allowances, corrected for the MSR actions (see above). Since the imbalances is calculated on an annual basis, we apply a scale factor of $8760^{-1}$ to avoid overly aggressive price updates. 
The REC price updates are calculated as follows, given RES target $R T_{y}$ in year $y$ :

$$
\forall y \in \mathcal{Y}: \lambda_{y}^{\mathrm{REC}, i+1}=\lambda_{y}^{\mathrm{REC}, i}-\frac{\rho}{8760 \cdot R T_{y}^{r e l}}\left(\sum_{r \in \mathcal{R}} \sum_{d \in \mathcal{D}} W_{d} \sum_{h \in \mathcal{H}} g_{y, d, h, r}^{\mathrm{R}}-R T_{y}\right),
$$

Only newly build capacity $\left(g_{y, r}^{\mathrm{R}, \mathrm{NB}, i}\right)$ receives these REC (Eq. (7)), however, the contribution of currently installed capacity in meeting the target is considered (Eq. (A.12)). Note the scaling factor $\left(8760 \cdot R T_{y}^{r e l}\right)^{-1}$, with $R T_{y}^{r e l}$ the relative RES target (e.g., 0.32) in year $y$, to keep all price updates in the same order of magnitude.

\section{Appendix A.5. Illustration of convergence}

Although ADMM-based methods are known for their good convergence properties (Höschle et al., 2017), obtaining an equilibrium may require solving several thousands of optimization problems, and hence entail a significant computational cost. To some extent, this process may be accelerated by tuning parameter $\rho$, which governs the price update and the penalty factor in the agents' objectives (Höschle, 2018; Boyd et al., 2011). In this particular setting, we observed the best trade-off between aggressive price updates and convergence by setting $\rho$ to $1.1 € / \mathrm{MWh}$ and $1.1 € /$ ton $\mathrm{CO}_{2}$. We did not explore iteration or market-specific $\rho$-values (Boyd et al., 2011) to speed up the convergence of the algorithm. To enhance the computational performance, we scale all emission-related variables to $\mathrm{MtCO}_{2}$ and all electricity related variables to GWh. In our sensitivity analysis, we use the result under reference assumptions as a starting solution to warm-start the algorithm. This approach ensures that deviations from this result are meaningful, i.e., that the equilibrium under reference assumptions is not an equilibrium in the sensitivity analysis.

Below, we illustrate the convergence of the ADMM algorithm in policy scenario 'MSR2018' under reference assumptions (Fig. A.7). Primal residuals related to the energy-only market and the RES-target are calculated on a per GWh-basis, whereas the primal residual in the ETS are expressed in $\mathrm{MtCO}_{2}$. Dual imbalances are all expressed in thousands of $€(\mathrm{k} €)$.

To reach the predefined tolerance with $\delta=10^{-2}$, approximately 13,387 iterations are required in this specific case. The primal residuals meet the stopping criterion sooner, i.e., after 9,577 iterations. Around the same number of iterations, the decision variables of the individual agents and the commodity prices converge to their equilibrium value, as illustrated for the electricity price, REC and ETS price in 2020 (Fig. A.7b), the cumulative investments in gas-fired and wind-based generation capacity (Fig. A.7c) and fuel shares of gas-fired and wind-based electricity generation in 2030 (Fig. A.7d). 


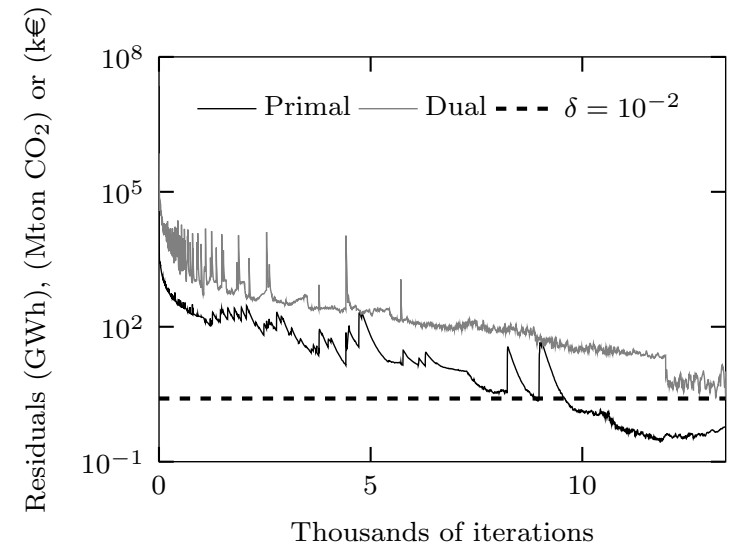

(a) Residuals

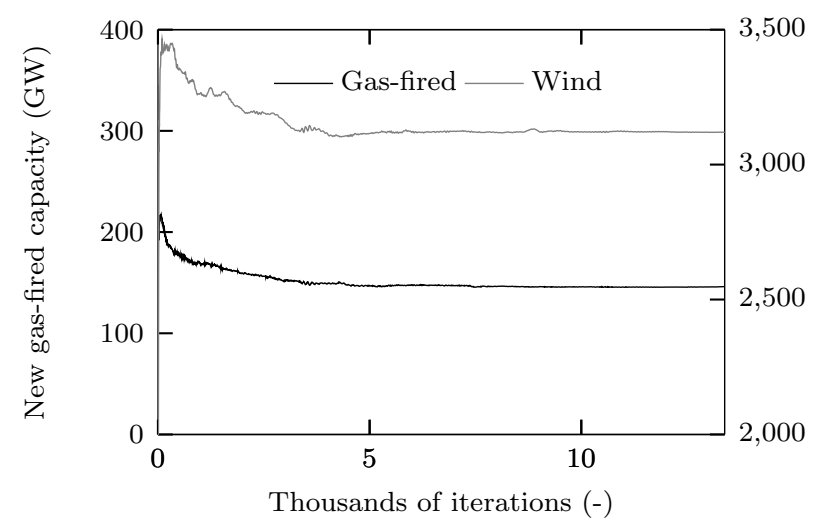

(c) Cumulative investment in new wind power or gas-fired power plant capacity in 2018-2061.

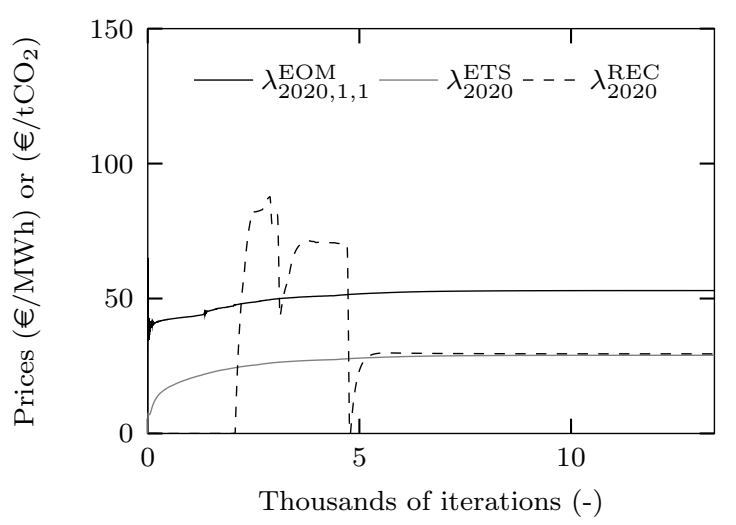

(b) Electricity, REC and ETS price in 2020

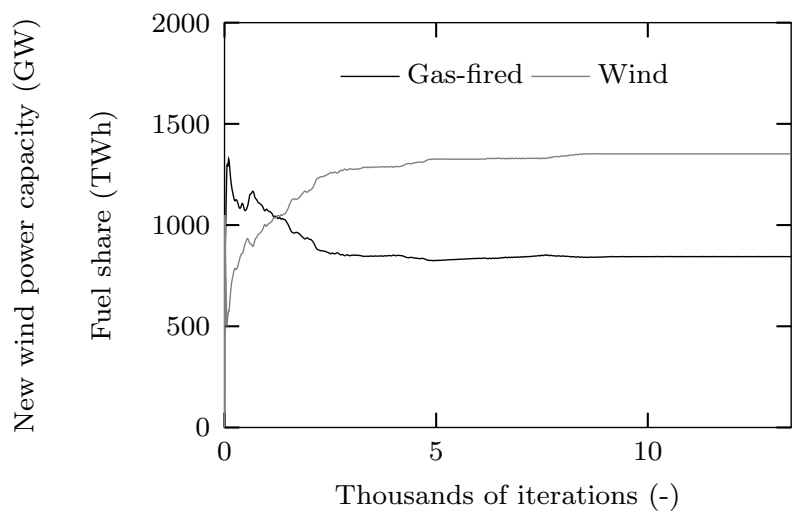

(d) Fuel share of wind-based or gas-fired electricity generation in 2030

Figure A.7. Convergence of the ADMM algorithm, as illustrated by the evolution of the primal and dual residuals (Fig. A.7a), the electricity, REC and EUA prices in 2020 (Fig. A.7b), the cumulative investment in new gas-fired generation and wind power plants (Fig. A.7c) and the fuel share of these technologies in 2030 (Fig. A.7d) in policy scenario 'MSR2018' under reference assumptions. 